\title{
Assessment of a personalized and distributed patient guidance system
}

\author{
Mor Peleg a,*, Yuval Shahar ${ }^{\mathrm{b}}$, Silvana Quaglini $^{\mathrm{c}}$, Tom Broens $^{\mathrm{d}}$, Roxana Budasu ${ }^{\mathrm{e}}$, \\ Nick Fung ${ }^{\mathrm{f}}$, Adi Fux ${ }^{\mathrm{a}}$, Gema García-Sáez ${ }^{\mathrm{g}}$, Ayelet Goldstein ${ }^{\mathrm{b}}$, Arturo González-Ferrer ${ }^{\mathrm{a}}$, \\ Hermie Hermens ${ }^{\mathrm{f}}$, M. Elena Hernando ${ }^{\mathrm{g}}$, Val Jones ${ }^{\mathrm{f}}$, Guy Klebanov ${ }^{\mathrm{a}}$, Denis Klimov ${ }^{\mathrm{b}}$, \\ Daniel Knoppel ${ }^{\mathrm{d}}$, Nekane Larburu ${ }^{\mathrm{f}}$, Carlos Marcos ${ }^{\mathrm{h}}$, Iñaki Martínez-Sarriegui ${ }^{\mathrm{g}}$, \\ Carlo Napolitano ${ }^{\mathrm{e}}$, Àngels Pallàs ${ }^{\mathrm{i}}$, Angel Palomares ${ }^{\mathrm{h}}$, Enea Parimbelli ${ }^{\mathrm{c}}$, Belén Pons ${ }^{\mathrm{j}}$, \\ Mercedes Rigla $^{j}$, Lucia Sacchi ${ }^{c}$, Erez Shalom ${ }^{b}$, Pnina Soffer ${ }^{a}$, Boris van Schooten ${ }^{f}$ \\ a Department of Information Systems, University of Haifa, Haifa, Israel \\ ${ }^{\mathrm{b}}$ Department of Information Systems Engineering, Ben Gurion University of the Negev, Beer-Sheva, Israel \\ c Department of Electrical, Computer and Biomedical Engineering, University of Pavia, Italy \\ ${ }^{\mathrm{d}}$ MobiHealth B.V., Enschede, The Netherlands \\ e IRCCS Foundation “Salvatore Maugeri”, Pavia, Italy \\ ${ }^{\mathrm{f}}$ University of Twente, 7500 AE, Enschede, The Netherlands \\ ${ }^{g}$ Bioengineering and Telemedicine Centre, Universidad Politécnica de Madrid, and Networking Research Centre for Bioengineering, Biomaterials and \\ Nanomedicine (CIBER-BBN), Spain \\ ${ }^{\mathrm{h}}$ Atos Spain S.A, Madrid, Spain \\ i Associacio de Diabetics de Catalunya,Barcelona, Spain \\ j Endocrinology and Nutrition Department Parc Tauli Sabadell University Hospital, Sabadell, Spain
}

\section{A R T I C L E I N F O}

\section{Article history}

Received 11 August 2016

Received in revised form 17 February 2017

Accepted 18 February 2017

\section{Keywords:}

Computer-interpretable clinical guidelines

Clinical decision-support systems

Patient guidance system

Mobile health

\begin{abstract}
A B S T R A C T
Objectives: The MobiGuide project aimed to establish a ubiquitous, user-friendly, patient-centered mobile decision-support system for patients and for their care providers, based on the continuous application of clinical guidelines and on semantically integrated electronic health records. Patients would be empowered by the system, which would enable them to lead their normal daily lives in their regular environment, while feeling safe, because their health state would be continuously monitored using mobile sensors and self-reporting of symptoms. When conditions occur that require medical attention, patients would be notified as to what they need to do, based on evidence-based guidelines, while their medical team would be informed appropriately, in parallel. We wanted to assess the system's feasibility and potential effects on patients and care providers in two different clinical domains.

Materials and methods: We describe MobiGuide's architecture, which embodies these objectives. Our novel methodologies include a ubiquitous architecture, encompassing a knowledge elicitation process for parallel coordinated workflows for patients and care providers; the customization of computerinterpretable guidelines (CIGs) by secondary contexts affecting remote management and distributed decision-making; a mechanism for episodic, on demand projection of the relevant portions of CIGs from a centralized, backend decision-support system (DSS), to a local, mobile DSS, which continuously delivers the actual recommendations to the patient; shared decision-making that embodies patient preferences; semantic data integration; and patient and care provider notification services.

MobiGuide has been implemented and assessed in a preliminary fashion in two domains: atrial fibrillation (AF), and gestational diabetes Mellitus (GDM). Ten AF patients used the AF MobiGuide system in Italy and 19 GDM patients used the GDM MobiGuide system in Spain. The evaluation of the MobiGuide system focused on patient and care providers' compliance to CIG recommendations and their satisfaction and quality of life.

Results: Our evaluation has demonstrated the system's capability for supporting distributed decisionmaking and its use by patients and clinicians. The results show that compliance of GDM patients to the most important monitoring targets - blood glucose levels (performance of four measurements a
\end{abstract}

\footnotetext{
Abbreviations: AF, atrial fibrillation; CIG, computer interpretable clinical guidelines; DSS, decision support system; EHR, electronic health record; GDM, gestational diabetes mellitus; mDSS, mobile DSS; PHR, personal health record.

* Corresponding author at: Dept. of Information Systems, University of Haifa, 3498838, Israel.

E-mail address: morpeleg@is.haifa.ac.il (M. Peleg).
} 
day: $0.87 \pm 0.11$; measurement according to the recommended frequency of every day or twice a week: $0.99 \pm 0.03)$, ketonuria $(0.98 \pm 0.03)$, and blood pressure $(0.82 \pm 0.24)$ - was high in most GDM patients, while compliance of AF patients to the most important targets was quite high, considering the required ECG measurements $(0.65 \pm 0.28)$ and blood-pressure measurements $(0.75 \pm 1.33)$. This outcome was viewed by the clinicians as a major potential benefit of the system, and the patients have demonstrated that they are capable of self-monitoring - something that they had not experienced before. In addition, the system caused the clinicians managing the AF patients to change their diagnosis and subsequent treatment for two of the ten AF patients, and caused the clinicians managing the GDM patients to start insulin therapy earlier in two of the 19 patients, based on system's recommendations. Based on the end-of-study questionnaires, the sense of safety that the system has provided to the patients was its greatest asset. Analysis of the patients' quality of life (QoL) questionnaires for the AF patients was inconclusive, because while most patients reported an improvement in their quality of life in the EuroQoL questionnaire, most AF patients reported a deterioration in the AFEQT questionnaire.

Discussion: Feasibility and some of the potential benefits of an evidence-based distributed patientguidance system were demonstrated in both clinical domains. The potential application of MobiGuide to other medical domains is supported by its standards-based patient health record with multiple electronic medical record linking capabilities, generic data insertion methods, generic medical knowledge representation and application methods, and the ability to communicate with a wide range of sensors. Future larger scale evaluations can assess the impact of such a system on clinical outcomes.

Conclusion: MobiGuide's feasibility was demonstrated by a working prototype for the AF and GDM domains, which is usable by patients and clinicians, achieving high compliance to self-measurement recommendations, while enhancing the satisfaction of patients and care providers.

(C) 2017 Elsevier B.V. All rights reserved.

\section{Introduction}

In the modern era, an increasing number of patients want to play an active role in their own health care; they want to be informed, seek information on their own, and be involved in decisions regarding their health. As one of the leaders of patient empowerment, cancer survivor Dave deBronkart, known as "e-Patient Dave", has said in his book "Let Patients Help" [1], there should be a partnership between the patients and their medical professionals. Empowerment occurs when healthcare professionals increase the capacity of patients to think critically and make autonomous, informed decision, such as make self-selected changes related to weight, nutrition, and physical activity, as part of a diabetes education [2], which increases their compliance and the chance that their health will improve or be maintained without unnecessary risks. Following this movement, developers of healthcare IT systems are developing more and more systems that are used directly by patients $[3,4]$.

Aujoulat et al. [5] explain that when patient empowerment is seen from the point of view of the provider-patient interaction, empowerment is considered as a process of communication and education in which knowledge, values, and power are shared. From the point of view of the patient, empowerment is a process of personal transformation, in which the patient develops general psychosocial skills of self-efficacy and attitudes toward his chronic condition. In the empowerment process, patients take control and responsibility for the successful management of their disease [6].

Kuijpers et al. [7] reviewed the literature regarding interactive Web-based interventions, focusing on interventions aimed at increasing patient empowerment and physical activity for various chronic conditions. They found that commonly used interventions included education, self-monitoring, feedback/tailored information, self-management training, personal exercise program, and communication (e.g., chat, email, patient portals) with either health care providers or patients. Internationally, there has been a rise in the number of health information systems and technologies that are being developed to support patient care. Borycki et al. [8] note that the amount of health information available on the World Wide Web and the use of mobile phone software to support consumer health behaviors and self-management of chronic illnesses have grown, but they note the need to maintain the safety of these applications.

A promising instrument for increasing the quality of care, limiting unjustified practice variation and saving costs are clinical practice guidelines (CPGs) [9]. Formalizing them as computerinterpretable guidelines (CIGs) [10] makes it possible to develop decision-support systems (DSSs) through application of these formalized models to patient data. In this way, patient-specific advice is provided at the point of care, increasing the chance of impacting clinician behavior compared to using only the narrative CPGs [11]. Traditionally, CIG-based DSSs have been developed for care providers; hence, although they have provided support for patientcentered care, they have not been used to empower patients.

Our multi-national research group integrates multiple types of clinical decision-support expertise, from informatics professionals, including experts on CIGs and tele-monitoring applications, through clinical-domain experts, to a patient advocacy group. At an early phase, we had understood that what chronic patients (or patients with conditions lasting for at least several months, such as pregnancy) really want is to lead their normal daily lives in their normal environment, while feeling safe because their health state is being continuously monitored. When conditions occur that require medical attention, they want to be notified at real time as to what they need to do, founded on evidence-based guidelines, while their medical team should be informed appropriately in parallel. From this understanding emerged the vision of the MobiGuide Project: "Guiding Patients Any Time, Everywhere" (http://www.mobiguideproject.eu/). MobiGuide is a large-scale integrated project in the Seventh Framework Programme (FP7) of the European Union.

The MobiGuide patient guidance system [12] includes a ubiquitous, distributed, and personalized DSS based on evidence-based CIGs [10], which is used by patients and their care providers. Rather than invite patients to clinics for long monitoring sessions, we provide them with a body area network of mobile sensors (e.g., ECG, blood pressure (BP), blood glucose (BG), physical activity sensors) and a smart phone, from which, assisted by a network of decisionsupport servers, the patients receive decision-support services.

The overall objectives of the MobiGuide system and the means for achieving them are briefly reviewed at the beginning of the Methods section. 
The specific objective of this paper is to evaluate whether the initial deployment of the MobiGuide system, for two very different clinical domains, each within a different European nation, has achieved three main important outcomes: (a) high patients' and care providers' compliance to clinical-guideline based monitoring reminders and recommendations, (b) high patients and care providers' satisfaction, and (c) increased patients' quality of life.

\section{Material and methods}

We shall start by reviewing the architecture of the MobiGuide system, the implementation of that system as evaluated in this study, and the study populations. The methodology for the personalization of the therapy for each patient was evaluated in a different study [13].

\subsection{The MobiGuide system}

MobiGuide is a remote chronic-patient management system that has five main objectives:

(1) increasing patient safety and quality of care through provision of personalized ubiquitous decision-support to the patients, by considering their preferences and their psychosocial and demographic context, to empower the patients and increase their compliance. To support this objective, contexts that are relevant to a patient-centered mobile DSS, and respective recommendations for them, are added to the formalized CIGs during a customization step [14]. During the first encounter of the patient with her care-provider, CIG personalization occurs when they define which specific events or concepts in the patient's life might induce any of the pre-defined CIG-customized contexts;

(2) semantic data integration into a personal health record (PHR), to allow the DSS system to uniformly access data from multiple sources, including electronic health records (EHRs), sensor data, patient-reported symptoms, and abstractions and recommendations output by the DSS;

(3) creation of a generic architecture [12,14] that supports interoperation with a variety of portable sensors, and different hospital EHRs in different clinical domains, and which includes patients and clinicians as users (who have respective user interfaces). Our decision-support services [11] include traditional services such as Knowledge Services that connect the DSS to the CIG knowledge base, Data Services which are used to retrieve the data from the PHR, Data Analysis Services, which are used to analyze temporal patterns, and Logging Services, to store the DSS trace. We also added several novel services in addition to those identified in [11], such as: 1) Signal Processing Services to analyze the data coming from sensors; 2) Shared Decision Services to support a shared decision by the physician and the patient; 3) Compliance Checking Services (part of the data analysis) to retrieve the patients' responses to the DSS recommendations; and 4) Knowledge to Data Mapping Services [15] which map CIG knowledge to PHR data;

(4) distribution of the decision support, between a mobile DSS (mDSS) that runs on the patient's smart phone and a backend DSS that is accessible via the Internet by the patients' care providers: to enhance efficiency and self-sufficiency, we want much of the DSS's computation to be local to each patient, based only on that patient's data; on the other hand, we wish to preserve the ability to maintain a large-scale evidence-based knowledge base that is relevant to all patients, and the ability to refer to each patient's historical electronic medical record. The backend DSS can also call a decision-tree module for shared decision-making, which determines a global preference of a particular CIG branch.

The backend DSS consists of the PICARD CIG application engine $[16,17]$ and the temporal-abstraction mediator [18] which mediates queries regarding the patient's time-oriented data or their abstractions, between PICARD and the PHR. The Backend DSS has access to the full knowledge base of CIGs and to the complete, historical PHR [19]. Based on the current state of the patient and of the system (e.g., battery level, bandwidth), the Backend DSS projects $[20,21]$ an appropriate part of its knowledge, using a specially developed generic projection language, to the mDSS, which can then deliver decision-support to the patient even when there is no connectivity to the internet, based on projected knowledge, the sensor data, the patient's preferences and daily schedule (e.g., meal times, reminder times), and data entered by the patient himself;

(5) performance of intelligent data analysis, to discover clinical data patterns in individual patients, thus providing additional decision-support.

The MobiGuide system can act in one of two modes to provide guidance whenever needed: interactive, or user-initiated mode (when a session with the DSS is initiated by a user (whether patient or care provider) during patient-provider encounters), and proactive, or system-initiated mode (when alarming situations are detected by the system, and it sends messages to the patient and his/her care providers).

The MobiGuide system meets these objectives and harnesses its technology to support patient-empowering functionality, summarized in Table 1.

\subsection{The MobiGuide implementation evaluated in this study and the study population}

We implemented the MobiGuide system in two clinical domains: GDM (with and without hypertension) and AF, relying on clinical practice guidelines [31-34] and customizing them to psychosocial context of patients and to the technological context of the MobiGuide system.

The AF and GDM domains vary in terms of intensity of monitoring: more intense monitoring of ECG in AF (daily sessions of $30 \mathrm{~min}$ ) relative to measuring up to four discrete measurements a day of BG for GDM. Both the ECG monitor and the glucose meter had a Bluetooth connection to the smart phone. The data from the phone was downloaded to the PHR on the backend when Internet connection was available; patients were advised to download data daily for the AF domain and at least every 3 days in the GDM domain.

In the AF domain, some patients were prescribed additional optional monitoring, including BP, INR for patients taking anticoagulants, weight and exercise. BP, INR, and weight measurements were entered manually by the patients. The Quality of Data Broker component of the MobiGuide system checked all of the manually entered data to ensure they were reliable, good quality measures. The prescribed frequency of measurement depended on patient context, as shown in Table 2. Patients could choose to turn off measurement or medication reminders for a given context but ECG reminders were always delivered. Medication reminders were delivered for all medications that the patient was taking, including those for comorbidities. A patient could either accept the reminder, indicating that he took the medication, or report non-compliance and select the reason for non-compliance.

In the GDM domain, in addition to measuring their BG via the glucose meter, all patients were required to measure ketonuria in the urine and manually record the results in the app and to measure $\mathrm{BP}$ with a sphygmomanometer connected with Bluetooth to the smart phone twice a week. The patients could also manually enter 
Table 1

Patient-empowering innovative functionalities supported by the MobiGuide system.

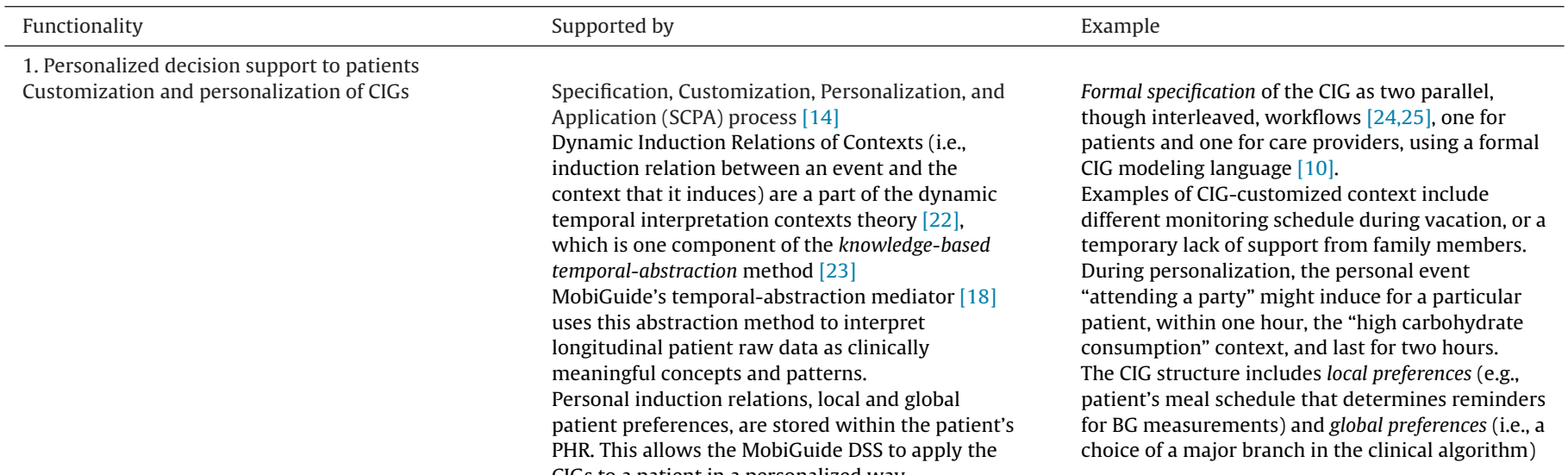

Patients are being monitored when clinically indicated

Measurement reminders sent at personalized times

Patient personalized events induce CIG context changes

Shared decision-making between the care provider and patient

Standard data models are used for data integration

Subscription/notification for detected data patterns

The patient and care providers view patient-specific CIG recommendations

The patient and care provider GUIs allow viewing recorded patient data

Patients may report their symptoms to the DSS

Integration of data from different sources and of different types
CIGs to a patient in a personalized way

CIG contains monitoring plans specifying frequency of measuring. Care provider can prescribe such plans for his/her patients

After personalization is done by the physician at patient enrollment, measurement schedules customized for a particular context are enforced by the mDSS accordingly

During enrollment, the care provider links patient personal events to CIG-customized contexts. The patient can set a current context, upon which Backend DSS is notified and activates the relevant plan which is projected to the mDSS

Care providers invoke the shared decision-making module to elicit patient's personal utilities for different health states which may result from treatment [26-28]. The most suitable option for the patient is recommended. The doctor can then select that option, storing it in the PHR

2. Semantically-integrated and secure Personal Health Record (PHR)

DSS recommendations, temporal abstractions (interpretations of raw, time-stamped data) detected in the PHR data, patterns found in sensor data, and data entered by patients or physicians is integrated into the PHR

The PHR is modeled through the HL7's virtual medical record [29] standard.

This enables the system's components (e.g., the DSS, the patient GUI) to use generic data insertion methods [19] in order to insert data into the PHR according to the HL7 virtual medical record structure.

The PHR includes notification services that allow subscribed system components to respond to events that are represented by particular data insertions [30], thus supporting the DSSs' proactive mode.

Recommendations suggested to the care provider by Backend DSS via the care provider GUI are saved in the PHR and can be accepted by clinicians. Recommendations that the mDSS initiated directly are also saved in the PHR

Monitoring data, and in the case of continuously monitored data - their abstractions, sent from the sensors to the smart phone via Bluetooth connection that are saved in the PHR, measurements, symptoms and context changes reported by the patient

Patients use their GUI to report symptoms, which are saved in the integrated PHR
Monitoring BG, ketonuria, and BP are mandatory for GDM patients. ECG is mandatory for AF patients and optional monitoring of BP, weight, INR, and physical activity could be prescribed Reminder to measure BG level $1 \mathrm{~h}$ after breakfast is sent $10 \mathrm{~min}$ (time gap set by patient) before $9 \mathrm{am}$ (as patient set her preferred breakfast time on week days to be $8 \mathrm{am}$ )

For Maria, the event of reporting about taking a vacation induces the context of semi-routine schedule during the vacation's period, resulting in the activation of a plan with two (rather than one) daily BP measurements

One decision tree compares the options of Warfarin, Aspirin, or Dabigatran. The shared decision-making module allows elicitation of personalized utility coefficients and calculates which treatment has highest quality-adjusted life years

DSS recommendations include medications and monitoring prescriptions

Data entered by patients includes weight measurements, reported symptoms, etc.

Data entered by clinicians: acceptance of proposed DSS recommendations

ObservationResult is used to store monitoring and patient-reported data, such as increased consumption of carbohydrates.

ProcedureProposal stores recommendations delivered from the DSS to clinicians and ProcedureOrders are stored and delivered to patients after clinicians' agree to proposals In the example above, the DSS subscribes to be notified when the care providers accepts or denies the recommendation from the DSS

Recommendations for patients include reminders for drugs, exercise and measurements, ECG monitoring when symptoms are entered, re-entry of low quality measurements.

Recommendations for care providers include starting insulin, cardioversion advice, etc. e.g., weight, exercise done by the patient, BG data, ketonuria reported by patients, etc.

$\mathrm{AF}$ patients may report symptoms such as unacceptable level of palpitation; GDM patients may report eating too many carbohydrates in a particular meal 
Table 1 (Continued)

\begin{tabular}{|c|c|c|}
\hline Functionality & Supported by & Example \\
\hline Establishing high quality of data & $\begin{array}{l}\text { The Quality of DataBroker, within the mDSS, has } \\
\text { device performance-related knowledge (e.g. } \\
\text { normal ranges) and if it detects performance } \\
\text { disruptions; it assigns them metadata of low } \\
\text { quality of data and triggers data reentry requests }\end{array}$ & $\begin{array}{l}\text { Quality of Data thresholds are defined for all } \\
\text { numeric data that may be entered manually, such } \\
\text { as weight, and sensor data which by default are } \\
\text { entered automatically via Bluetooth connection, } \\
\text { such as heart rate }\end{array}$ \\
\hline $\begin{array}{l}\text { Maintenance of patient privacy and security \& } \\
\text { awareness }\end{array}$ & $\begin{array}{l}\text { Privacy by design is achieved by separating data } \\
\text { from identifiable information both in the PHR and } \\
\text { in the mobile. Authentication and authorization } \\
\text { mechanisms are used; awareness services allow } \\
\text { patients to see who viewed their data }\end{array}$ & $\begin{array}{l}\text { Multi-factor authentication, secure, auditable } \\
\text { access to data complying with data protection } \\
\text { requirements. Single component (PII hub) storing } \\
\text { all patient identifiers in a secure, centralized hub } \\
\text { which is logically and physically separated from } \\
\text { the clinical data. Enhanced levels of trust from } \\
\text { users by perception of security and privacy } \\
\text { features }\end{array}$ \\
\hline
\end{tabular}

3. Generic patient-centered architecture, interoperable with different sensors and EHRs

The architecture has six high-level functional Including (a) interfaces to hospital EMRs, Patients, components and Clinicians, (b) CIG knowledge base, (c) Distributed DSS, (d) Body Area Network (consisting of wearable sensors, signal analysis algorithm, a Quality of Data Brokering component a mobile DSS (mDSS), and a mobile device with the patient GUI), (e) semantically-integrated PHR, and (f) security and privacy functionalities. The system was developed in a generic way such

Ability to apply the architecture to other clinical domains
4. A distributed and coordinated DSS

Allowing ubiquitous decision-support
The mDSS is coordinated with the Backend DSS by the projection mechanism, and can operate also independently when there is no Internet connectivity. In cases of low quality of service, functionality can be delegated to other components or sessions postponed The backend DSS controls which relevant care plans are projected to the mDSS

The mDSS enacts proposed plans at specific times, in accordance with the patient's preferences and daily routine, as entered into the mDSS by the patient

Embedded within each projection is a special "Callback" temporal pattern that the mDSS keeps monitoring for, which signals the mDSS that there is a need for seeking additional assistance from Backend DSS.
The same architecture was used to support atrial fibrillation patients and providers in Italy and gestational diabetes patients in Spain. The AF patients used mobile ECG sensors and the GDM patients used mobile glucose meters and BP meters.

When the battery is low the AF patient is advised via the Quality of Data Broker to charge the ECG sensor and delay exercise so that his safety can be achieved through monitoring.

A pattern such as two episodes of positive ketonuria within one week, may signal a callback. When the mDSS detects the Callback pattern in the patient data, it initiates a CallBack action to the Backend DSS. Backend DSS then sends a new projection to the mDSS to halt the existing monitoring plan of two measurement reminders for Ketonuria per week, and activates the daily monitoring plan.

5. Intelligent data analysis for discovering clinical data patterns in individual patients for purposes of decision-support

Patient safety

Important interval-based temporal patterns in the data, requiring attention, are detected by the temporal Mediator according to CIG declarative knowledge and saved in the PHR, resulting in proactive advice delivered to patients and care providers

The temporal Mediator subscribes to receive notifications from the PHR when a temporal pattern is detected as soon as the last data item completing the pattern arrives

AF events are detected locally at the mDSS, by the $\mathrm{AF}$ detection algorithm
2 BG values $>140 \mathrm{mg} / \mathrm{dL}$ in the past week notify care provider to consider insulin and patient to see her doctor.

Detected AF episodes are reported to the physician in daily reports. The doctor can decide whether to intensify treatment

See also example above
BP measurements if they chose to do so. Physical activity monitored via the MobiGuide system could be suggested to patients. If the Bruce protocol (a test for evaluating cardiac function in exercising patients) has been executed for a patient, the necessary data for monitoring the exercise (e.g., upper threshold for heart rate) were already in the PHR. If not, they were to be entered at the moment of the exercise prescription. However, in our study, clinicians had not prescribed exercise monitoring for any of their patients.

All of the monitoring plans (in AF and GDM) were part of the CIGs.
The study involved ten AF patients from IRCCS Foundation "Salvatore Maugeri”, Pavia, Italy and twenty gestational GDM patients from Parc Tauli Sabadell University Hospital, Sabadell, Spain. The study began on April 1, 2015 and ended on December 31, 2015. One of the GDM patients dropped out after one week. Informed consent was obtained from patients and authorization was obtained from the ethical committees of the hospitals for experimentation with human subjects. As a control group for GDM, we referred to data from a historical group of 247 patients, similar in characteristics, who had been followed up during 2010-2013 at the same GDM clinic [35]. 
Table 2

Monitored concepts (raw or abstract) in different contexts for the AF and GDM domains.

\begin{tabular}{|c|c|c|}
\hline Context & Monitored concept & Monitoring frequency \\
\hline $\begin{array}{l}\text { AF } \\
\text { Routine (Regular physical exercise) }\end{array}$ & $\begin{array}{l}\text { ECG } \\
\text { BP } \\
\text { INR } \\
\text { Weight } \\
\text { Exercise } \\
\text { Medication non compliance }\end{array}$ & $\begin{array}{l}1 / \text { day for } 30 \text { min } \\
1 / \text { day for hypertensive patients (going down to } \\
2 / \text { week if BP values are good for one week) } \\
1 / \text { week for non-hypertensive } \\
1 /(2 \text { week) } \\
1 / \text { week } \\
\text { Depending on patient } \\
\text { As prescribed }\end{array}$ \\
\hline Semi routine (Regular physical exercise) & $\begin{array}{l}\text { BP } \\
\text { All other concepts }\end{array}$ & $\begin{array}{l}\text { 2/day for hypertensive patients } \\
1 \text { /week for non-hypertensive } \\
\text { As in routine context }\end{array}$ \\
\hline Doctor wants close monitoring & $\begin{array}{l}\text { ECG monitoring freq } \\
\text { All other concepts }\end{array}$ & $\begin{array}{l}\text { Wear } 24 \mathrm{~h}, 3 \text { days a week } \\
\text { As in semi-routine context }\end{array}$ \\
\hline Excessive physical exercise(risk of AF events) & $\begin{array}{l}\text { ECG monitoring freq } \\
\text { All other concepts }\end{array}$ & $\begin{array}{l}2 / \text { day for } 30 \mathrm{~min} \\
\text { As in semi-routine context }\end{array}$ \\
\hline $\begin{array}{l}\text { GDM } \\
\text { Regular }\end{array}$ & $\begin{array}{l}\text { BG } \\
\text { Ketonuria } \\
\text { BP } \\
\text { Weight } \\
\text { Exercise }\end{array}$ & $\begin{array}{l}\text { 4/day, daily } \\
1 / \text { day } \\
2 / \text { week } \\
1 / \text { week } \\
\text { Depending on patient }\end{array}$ \\
\hline Good BG values for a month & BG & 4/day, twice a week \\
\hline Negative ketonuria for 2 weeks & Ketonuria & 2/week \\
\hline Good BP values for 2 weeks & $\mathrm{BP}$ & 1/week \\
\hline
\end{tabular}

The patient user populations for the two clinical domains were different: pregnant women, 35 years of age, who are more educated and use computers and smart phones more than the older AF patients.

The CIGs created for these two domains, as well as the DSS module that is mostly used to control decision-support and interplay between the centralized and the local DSS modules are significantly different. The most significant difference is that the GDM CIG includes much more interaction between the mDSS and Backend DSS (which reflects the higher level of involvement of the Backend DSS in decision support) and contains more temporal patient data patterns that are being monitored by the system relative to the AF CIG. On the other hand, context changes affect the AF monitoring plans more than just changing reminder times.

Another difference is that the AF CIG also contains three decision-support modules for the care provider: cardioversion advice, shared decision-making for anticoagulation therapy and shared decision making for ablation vs. anti-arrhythmic drug treatment. Shared decision-making is not represented as an Asbru CIG but as decision trees.

Table 3 shows the description of the key monitored temporal patterns in the two CIGs and the consequent plan activation or notification. The notifying agent documents the notification in the PHR. The complete list of patterns and notifications (recommendations) is provided in [36]. As shown in Table 3, most of the plans concern patient monitoring. Table 3 also shows the cardioversion plans that support the care provider.

\subsection{Methods for assessing compliance of users to clinical guidelines}

Clinical guidelines based recommendations to patients consisted of reminders for monitoring and taking medications as well as decision-support recommendations.

\subsubsection{Assessment of compliance to monitoring prescriptions}

We assessed the compliance (i.e., the proportion of measurements that had been performed by the patient) for those patients who were prescribed to monitor measurements. For AF patients, this included ECG sessions lasting at least $20 \mathrm{~min}$, BP, INR, and weight. For GDM patients on the MobiGuide group, this included BG, ketonuria, and BP. For the historical cohort of GDM patients, this included compliance to BG measurements. In addition, physical activity monitoring and weight measurement was recommended for GDM patients, but not prescribed. We also assessed the amount of medication non-compliance reported by AF patients, assuming that if the patient clicked to confirm that he had taken the medication, this was a true report. We performed the analysis separately for periods of time in which the patient changed context for $\mathrm{AF}$ patients or the monitoring plan was changed for GDM patients.

To assess compliance to monitoring, we calculated for each patient the actual number of measurements done per monitoring period (day, week, or two weeks) with the planned number of measurements for that period, according to the monitoring plan (see Table 2). Then we divided the number of measurements per period by the total planned number of measurements. Finally, we took the mean of the individual compliance of all patients.

\subsubsection{Aggregation of clinical parameter values that were monitored by the cohorts of patients}

We also report aggregated results of the clinical parameters that were monitored (e.g., BP, BG) for the whole period of monitoring. We report the mean of all of the patients' mean values in order to give each patient the same weight. This is because patients had different number of measurements and we do not want to give patients with more measurements a higher weight.

\subsubsection{Assessment of compliance to ECG monitoring as a function of trigger type}

However, in our analysis of the effect of the different types of ECG triggers, we considered all ECG monitoring sessions from all of the patients together because we wanted to assess the correlation between the proportion of positive AF episodes detected and the different triggers for measuring the ECG: a scheduled reminder vs. a patient-initiated monitoring vs. a response to a system recommen- 
Table 3

Monitored patterns and plan activation or notification in the GDM and AF CIGs.

\begin{tabular}{l} 
Monitored pattern \\
\hline GDM
\end{tabular}

2 abnormally-high BG values in a week

High BG values measured by glucose meter

Four weeks of good glycemia control

Positive ketonuria

Two weeks of negative ketonuria

Two weeks of good BP

Change of context

$\mathrm{AF}$

Doctor changed prescription

Time to remind about taking medications

Patient reported an AF symptom

Patient has scheduled an event at risk for bleeding

Context switch to routine schedule in hypertensive patient

Context switch to semi-routine schedule in hypertensive patient

Switch to excessive physical exercise context

Switch to close monitoring context

Hypertensive patient in routine context had 2 consecutive abnormal

BP values

Hypertensive patient in routine context had only normal BP values for one week

Doctor activated cardioversion advice

*Class ranges from I (benefits much greater than risks) to III (risks much greater than benefits)

Level is a measure of the supporting scientific evidence $(A>B>C)$
Notification (recommendation)/Plan activation

Patient notification: "Your last BG measurements weren't so good - you should visit your doctor in the next few days"; Care provider notification: "Consider starting insulin treatment"

Question delivered to patient: "There are some high BG values, did you eat more than you should have?". If answer is yes, and no previous notification was sent to the care provider then notification to care provider: "Change nutritional prescription"; if care provider was notified previously the new notification is "Consider starting insulin treatment"

Plan activation: Switch from daily BG schedule (of four measurements a day) to twice a week (of four measurements a day)

Question to patient: "Have you been eating your prescribed amount of carbohydrates?". If answer is yes, and no previous notification was sent then notify to patient: "Ketonuria has been positive; please increase your carbohydrates bedtime by 1 unit $(10 \mathrm{~g})$ ". If previous notification was sent then patient is notified "Ketonuria has been positive again. You should visit your doctor in the next few days" and doctor is notified "A meeting should be scheduled with the patient to balance diet"

Plan activation: Switch from daily ketonuria schedule to twice a week Plan activation: Switch from twice a week BP schedule to once a week Plan activation: change personal reminders timing. This change does not affect monitoring plans

Plan activation: change personal reminders

Notification sent to patient: please take your medication (name of medication) Notification (recommendation) sent to patient: please start a 30 min ECG monitoring session

Notification (recommendation) sent to patient: "Talk to your doctor to agree on the anticoagulation therapy management if the appointment for the risky procedure you will undergo in 5 days is confirmed"

Plan activation: Switch to measuring BP once a day for hypertensive patients Plan activation: Switch to measuring BP twice a day for hypertensive patients Plan activation: Switch to 2 daily 30-min ECG monitoring sessions

Plan activation: Switch to 24-h ECG monitoring

Plan activation: Switch to measuring BP once a day

Plan activation: Switch to measuring BP twice a week

Notifications sent to care provider:

Electrical cardioversion is contraindicated in patients with digitalis toxicity or hypokalemia. (Class III, Level C)*; Cardioversion is recommended in patients without hemodynamic instability when symptoms of AF are unacceptable to the patient. In case of early relapse of AF after cardioversion, repeated direct-current cardioversion attempts may be made following administration of antiarrhythmic medication (Class I, Level C); Direct-current cardioversion can be useful to restore sinus rhythm as part of a long-term management strategy for patients with AF (Class IIa, Level B); Before initiating antiarrhythmic drugs, treatment of precipitating or reversible causes of $\mathrm{AF}$ is recommended (Class I, Level C); Keep taking Oral Anticoagulant Therapy up to 3 weeks in preparation to cardioversion dation to measure ECG because an AF symptom had been reported by the patient. The values that we report from these measurements are the ratio of ECG sessions in which the algorithm has detected AF for at least $10 \%$ of the session. In our analysis of the proportion of AF positive sessions we excluded one patient (patient \#9) who had permanent $A F$ and skewed the results because obviously all of the ECGs measured by this patient were AF positive.

To assess the compliance to ECG monitoring that was initiated by patients' symptom reporting, we checked (a) that at least one of the following symptoms had a value different form 'absent': palpitations, dyspnea, fatigue, lightheadedness, symptomatic hypotension, polyuria, syncope, chest pain; (b) that the monitoring session started within $20 \mathrm{~min}$ from the reported symptom, and that it lasted at least $20 \mathrm{~min}$; (c) in addition, we interpolated between symptoms that were spaced up to an hour apart, assuming that they were all related to the same episode and thus a single symptom-triggered ECG monitoring session was indicated.

It should be noted that our cardiologist has examined in detail 24 ECG strips from six patients with positive and negative occurrences of AF (according to the AF algorithm). He has determined both the sensitivity and specificity to be around 0.64 .

We used two-tailed proportion test to test the difference between compliance of patients to system-initiated routine reminders and to system-initiated triggers in response to patient's symptom reporting. The same test was used to test the difference in the proportion of $\mathrm{AF}+$ episodes detected in ECG sessions that were initiated by patients, system-initiated triggers in response to patient's symptom reporting, or system-initiated routine reminders measurements.

\subsubsection{Compliance assessment for BG monitoring by GDM patients}

To assess compliance of GDM patients with BG monitoring, two aspects were considered: a) the number of daily measurements done by the patient (which were always prescribed to be four) and b) compliance to measure according to frequency of the active monitoring plan (e.g., twice a week or daily). 
Table 4

Summary of compliance to reminders and recommendations for AF patients.

\begin{tabular}{|c|c|c|c|c|c|}
\hline Row\# & & $\begin{array}{l}\text { \# patients prescribed/to which } \\
\text { clinical recommendations } \\
\text { were delivered }\end{array}$ & $\begin{array}{l}\text { Compliance (Mean of } \\
\text { all patients' means) }\end{array}$ & $\begin{array}{l}\text { Frequency of } \\
\text { recommendations } \\
\text { (\#recommendations) }\end{array}$ & $\begin{array}{l}\text { Mean value over all } \\
\text { patients' means } \\
\text { ( } \pm \text { standard deviation })\end{array}$ \\
\hline & Monitoring plans & & & & \\
\hline R1 & ECG & 10 ( 4 changed context) & $\begin{array}{l}0.65 \pm 0.28 \\
(0.75 \pm 0.2)\end{array}$ & 1/day & $\begin{array}{l}\text { Proportion of } \mathrm{AF}+ \\
\text { episodes: } \\
0.13 \pm 0.28 \\
(0.13 \pm 0.13) \\
\text { *excluding patient with } \\
\text { permanent } \mathrm{AF}(\# 9)\end{array}$ \\
\hline $\mathrm{R} 1.1$ & $\begin{array}{l}\text { ECG in response to } \\
\text { system-initiated routine } \\
\text { reminders }\end{array}$ & 9 & $\begin{array}{l}0.52 \\
(=729 / 1396)\end{array}$ & $\begin{array}{l}\text { 1/day } \\
\text { (1396 for } 9 \text { patients) }\end{array}$ & $0.12(88 / 729)$ \\
\hline $\mathrm{R} 1.2$ & $\begin{array}{l}\text { ECG in response to } \\
\text { patient-initiated sessions }\end{array}$ & 9 & $\begin{array}{l}\text { NA (not a } \\
\text { recommendation) }\end{array}$ & $\begin{array}{l}\sim 0.9 / \text { week } \\
\text { (391 such ECGs) }\end{array}$ & $0.19(34 / 177)$ \\
\hline $\mathrm{R} 1.3$ & $\begin{array}{l}\text { ECG in response to system } \\
\text { initiated in response to } \\
\text { patient's symptom reporting }\end{array}$ & 7 & $\begin{array}{l}0.56 \\
(=19 / 34)\end{array}$ & $\begin{array}{l}\sim 0.7 / \text { month } \\
(34)\end{array}$ & $0.74(14 / 19)$ \\
\hline R2 & $\mathrm{BP}$ & $8(3$ changed context)* & $\begin{array}{l}0.75 \pm 1.33 \\
(0.03 \pm 0.03)\end{array}$ & $\begin{array}{l}1 / \text { day } \\
\text { ( } 2 / \text { day for semi } \\
\text { routine) }\end{array}$ & $\begin{array}{l}\text { SBP: } 89.8 \pm 13.3 \% \text { in } \\
\text { normal range } \\
\text { DBP: } 97.3 \pm 3.7 \% \text { in } \\
\text { normal range }\end{array}$ \\
\hline R3 & INR & $\begin{array}{l}1 \text { (this patient changed } \\
\text { context)* }\end{array}$ & $0.64(0)$ & $1 / 2$ weeks & $100 \%$ in normal range \\
\hline R4 & Weight & 2 & $0.14 \pm 0.06$ & 1/week & $88.5 \pm 1.5 \mathrm{~kg}$ \\
\hline R5 & $\begin{array}{l}\text { Clinical recommendations } \\
\text { Drugs (reminders) }\end{array}$ & $6(4$ changed context)* & $\begin{array}{l}0.97 \pm 0.03 \\
(0.93 \pm 0.03)\end{array}$ & Daily & NA \\
\hline R6 & $\begin{array}{l}\text { Talk to your doctor about } \\
\text { changing anticoagulation } \\
\text { therapy due to the risky event } \\
\text { you reported }\end{array}$ & 1 & 1 & $\begin{array}{l}\text { Number } \\
\text { recommendations } \\
\text { delivered: } 1\end{array}$ & \\
\hline R7 & $\begin{array}{l}\text { Keep taking anticoagulant } \\
\text { before cardioversion }\end{array}$ & 1 & 1 & $\begin{array}{l}\text { Number } \\
\text { recommendations } \\
\text { delivered: } 1\end{array}$ & $\begin{array}{l}\text { Number } \\
\text { recommendations } \\
\text { delivered: } 1\end{array}$ \\
\hline
\end{tabular}

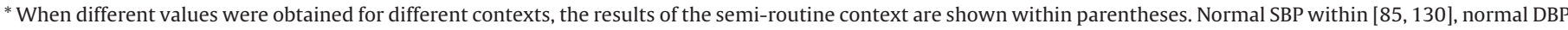

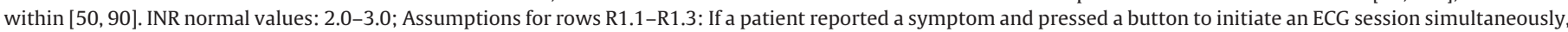

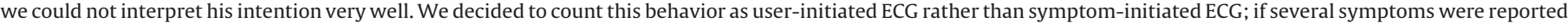
within $60 \mathrm{~min}$, then a single ECG session in response to symptom reporting would indicate compliance.

\subsubsection{Comparison of the GDM cohort to a historical GDM cohort}

We compared the MobiGuide's cohort of 19 GDM patients to that of a similar historical cohort of 247 patients, which was managed using the standard GDM clinic routine. Characteristics at diagnosis time, compliance to BG monitoring, the patient's metabolic and BP status, and pregnancy outcomes were collected from both cohorts (See Table 6).

Unlike the MobiGuide patients who received four reminders for BG measurements on each day that they should have measured BG, the historical cohort patients were told that they should be measuring at least 5 BG measurements a day. Therefore, compliance for the historical cohort was calculated by counting the number of BG measurements for each patient divided by the number of days that the patient was instructed to measure her BG. We therefore calculated a similar BG compliance for the MobiGuide patients, different than the two compliance measures described in the subsection above (compliance to 4 measurements a day and compliance to the recommended measuring frequency).

We used the t-statistic to assess whether the means of the two populations were significantly different in any of the parameters measured.

\subsubsection{Assessment of compliance to DSS recommendations}

We assessed the compliance of users (patients and care providers) to DSS recommendations by analyzing the PHR data, and the log files of Backend DSS and the smart phones. For each user we tracked the number of different recommendations delivered and followed. From it, we calculated the compliance, by consider- ing the response to a clinical recommendation type from all of the patients together.

Different types of recommendations were delivered.

\subsubsection{DSS recommendations to patients}

Patient received clinical recommendations/notifications (see examples in Table 3), questions to clarify their state in order to make specific recommendations (as shown in Tables 4 and 5), and technical recommendations. Technical recommendations included invitation to re-enter measurement values when their quality of data was low, notification that ECG monitoring sessions were shorter than the recommended $30 \mathrm{~min}$, and recommendation to charge the phone or sensors. Technical recommendations were not saved in the PHR, hence our analysis of compliance considered only clinical recommendations and question answering.

The number of clinical recommendations delivered to each patient was not high, and we wanted to assess the response to all of the recommendations, where each recommendation is equally important, rather than calculate the mean of mean patient values.

\subsubsection{DSS recommendations to clinicians}

Care providers received only clinical recommendations.

AF clinicians received two types of clinical recommendations in their GUI: cardioversion advice, and ECG summaries. For each ECG session, a summary report was generated, which included six data elements, ordered by date: start and end time of the ECG session, percentage of time spent in $\mathrm{AF}$ (more precisely, in irregular heartbeat), minimum, maximum and mean heart rate registered during the recording. The PHR stores data regarding how many times the 
Table 5

Summary of compliance and measured values for GDM patients.

\begin{tabular}{|c|c|c|c|c|}
\hline & $\begin{array}{l}\text { \# patients prescribed/to } \\
\text { which clinical } \\
\text { recommendations were } \\
\text { delivered }\end{array}$ & Compliance & $\begin{array}{l}\text { Frequency of } \\
\text { recommendations }\end{array}$ & $\begin{array}{l}\text { Average value over all } \\
\text { patients }\end{array}$ \\
\hline \multicolumn{5}{|l|}{ Monitoring plans } \\
\hline BG & 19 & $\begin{array}{l}\text { Compliance to } 4 \text { BG per day }{ }^{\mathrm{a}} \\
0.87 \pm 0.11 \\
\text { Compliance to BG monitoring } \\
\text { plan }^{\mathrm{b}} 0.99 \pm 0.03\end{array}$ & $\begin{array}{l}4 \text { BG per day } \\
1 / \text { day or } 2 / \text { week depending on } \\
\text { patient's glycemic values }\end{array}$ & $\begin{array}{l}\text { \% Normal fasting BG: } \\
94 \pm 4.48 \\
\% \text { Normal post-meal: } \\
86.4 \pm 8.9\end{array}$ \\
\hline BP & 19 & $\begin{array}{l}\text { Twice a week: } 0.91 \pm 0.16 \\
\text { Once a week: } 0.72 \pm 0.33 \\
\text { Weighted average: } 0.82 \pm 0.24\end{array}$ & $\begin{array}{l}1 / \text { week or } 2 / \text { week depending } \\
\text { on patient's BP values }\end{array}$ & $\begin{array}{l}\text { \% Normal SBP: } 95.0 \pm 7.1 \\
\% \text { Normal DBP: } 98.1 \pm 3.8\end{array}$ \\
\hline Ketonuria & 19 & $\begin{array}{l}\text { Once a day: } 0.96 \pm 0.06 \\
\text { Twice a week: } 1.0 \pm 0.00 \\
\text { Weighted average: } 0.98 \pm 0.03\end{array}$ & $\begin{array}{l}1 / \text { day or } 2 / \text { week depending on } \\
\text { patient's ketonuria values }\end{array}$ & $95.1 \%$ in normal range \\
\hline \multicolumn{5}{|l|}{ Clinical recommendations } \\
\hline $\begin{array}{l}\text { Q: High BG ( } 2 \text { abnormal per week). } \\
\text { Did you eat more than you } \\
\text { should? }\end{array}$ & 19 out of 19 prescribed & 0.31 & $\begin{array}{l}\text { Number of recommendations } \\
\text { delivered: } 51\end{array}$ & \\
\hline $\begin{array}{l}2 \text { high BG in a week. visit your } \\
\text { doctor }^{c}\end{array}$ & $\begin{array}{l}4 \text { patients out of } 19 \\
\text { prescribed }\end{array}$ & 0.5 & $\begin{array}{l}\text { Number recommendations } \\
\text { delivered: } 4\end{array}$ & \\
\hline $\begin{array}{l}\text { Q: Have you been eating your } \\
\text { prescribed amount of } \\
\text { carbohydrates? (ketonuria) }\end{array}$ & $\begin{array}{l}4 \text { patients out of } 19 \\
\text { prescribed }\end{array}$ & 0.5 & $\begin{array}{l}\text { Number recommendations } \\
\text { delivered: } 6 \text { ( } 2 \text { patients } \\
\text { received the recommendation } \\
\text { twice) }\end{array}$ & \\
\hline $\begin{array}{l}\text { Ketonuria has been positive; please } \\
\text { increase your carbohydrates } \\
\text { @bedtime }\end{array}$ & $\begin{array}{l}1 \text { patient out of } 19 \\
\text { prescribed }\end{array}$ & 1 & $\begin{array}{l}\text { Number recommendations } \\
\text { delivered: } 1\end{array}$ & \\
\hline $\begin{array}{l}\text { Ketonuria has been positive again. } \\
\text { You should visit your doctor in } \\
\text { the next few days }\end{array}$ & $\begin{array}{l}1 \text { patient out of } 19 \\
\text { prescribed }\end{array}$ & 0 & $\begin{array}{l}\text { Number recommendations } \\
\text { delivered: } 1\end{array}$ & \\
\hline
\end{tabular}

a Patient's compliance to measure 4 or more BG values per day (considering all the days when at least 1 measurement was done).

b Patient's compliance to follow BG monitoring plan (i.e., monitor BG every day or twice a week).

c This recommendation is sent to patients taking insulin or to patients replying "yes" to the question in the row above; Q-question; When different values were obtained for different monitoring plans, the results are shown separately. Compliance greater than 0.8 was considered high.

Table 6

Comparison of the GDM MobiGuide cohort with a historical GDM cohort.

\begin{tabular}{|c|c|c|c|c|}
\hline & $\begin{array}{l}\text { Historical cohort: mean and } \\
\text { standard deviation or percent }\end{array}$ & $\begin{array}{l}\text { MobiGuide: mean and } \\
\text { standard deviation or } \\
\text { percent) }\end{array}$ & $\begin{array}{l}\text { t-statistic } \\
\text { or (z-score) }\end{array}$ & p-value \\
\hline Age (years) & $34.0 \pm 4.5$ & $35.2 \pm 3.9$ & 1.130 & 0.2596 \\
\hline Pre-gestational weight (Kg) & $69.2 \pm 14$ & $69.8 \pm 13.1$ & 0.8567 & 0.181 \\
\hline Gestational week at first visit & $29.7 \pm 1$ & $29.0 \pm 5.4$ & -1.721 & 0.0865 \\
\hline Followup duration (days) & $63.3 \pm 40$ & $57.1 \pm 21.5$ & -0.667 & 0.5051 \\
\hline BG mean compliance ${ }^{a}$ & $\mathbf{0 . 8 7} \pm \mathbf{0 . 2 8}$ & $1.01 \pm \mathbf{0 . 1 0}$ & 2.166 & 0.0312 \\
\hline$\% \mathrm{BG}>140 \mathrm{mg} / \mathrm{dL}$ & $12.9 \pm 10$ & $13.6 \pm 9.2$ & 0.296 & 0.7678 \\
\hline$\%$ insulin therapy & 53.8 & 43.7 & $(0.8501)$ & 0.39532 \\
\hline Mean systolic BP (mmHg) & $119.3 \pm 12$ & $98.6 \pm 8.5$ & -7.372 & $<0.0001$ \\
\hline Mean diastolic BP (mmHg) & $72.8 \pm 9$ & $64.7 \pm 6.6$ & -3.841 & 0.0002 \\
\hline$\%$ Cesarean section & 25.1 & 14.3 & $(1.0573)$ & 0.28914 \\
\hline \% Instrumental delivery & 15.2 & 21.4 & $(-0.7169)$ & 0.4715 \\
\hline Birth weight (gram) & $3233 \pm 433$ & $3102 \pm 408$ & -1.276 & 0.2032 \\
\hline
\end{tabular}

a Patient's compliance to follow at least four BG measurements on indicated days according the monitoring plan (i.e., monitor BG every day or twice a week). Note that this compliance could be greater than 1 .

clinicians viewed the ECG summaries, even if we have no indication of which specific reports were inspected. In addition, the AF nurse accessed each ECG strip generated for all patients. But this was done using a desktop application for which we do not have log files, so results are presented based on the nurse' self-reporting.

GDM clinicians received recommendations related to starting insulin and changing a patient's diet based on BG and ketonuria results.

\subsection{Methods for assessing patient and care provider satisfaction}

Analysis of the users' interaction with the MobiGuide system is reported elsewhere [13]. Some of the results that pertain only to the patients' satisfaction are also reported in that study.
Patient and care provider satisfaction was assessed by two different end-of-study questionnaires using a set of questions (see Appendix B) to which users replied on a standard Likert scale of $1-5$.

\subsection{Methods for assessing enhancement in quality of life of $A F$ patients}

Two questionnaires were used to assess the quality of life of the AF patients: EuroQoL and AFEQT.

The validated EuroQoL 5D-5L questionnaire (http://www. euroqol.org/) contains five questions for assessing on a scale of 1-5 the impairment in mobility, ability to perform self-care, carry out the usual activities, degree of pain/discomfort, level of anxi- 
ety/depression. A lower score for each of the five concepts identifies less impairment. From those scores, a utility coefficient may be calculated, ranging from 0 to 1 . The questionnaire also contain a visual analogue scale in which the patient evaluates his overall quality of life on a scale of $0-100$.

The EuroQoL questionnaire was administered to AF patients before-and, periodically, during-the-use of MobiGuide. We present results of the questionnaires administered at the beginning and at the end of the study. The post analysis was made using the recent questionnaire(s) filled in by the patient using the smart phone. There was a case of one patient (patient 7) who answered several times the EuroQol during the last two weeks of the study. For this patient, we averaged the values of the last two weeks.

For the AF Effect on QualiTy-of-Life (AFEQT) questionnaire [37] it is possible to calculate specific scores concerning the patient's perception of the symptoms, the impact of AF on his/her daily activities, the treatment and the satisfaction with the treatment. The overall score is obtained as a synthesis of the first three scores. These scores range from 0 to 100 and a higher score reflects better quality of life.

\section{Results}

\subsection{Compliance assessment}

The average number of days that the patients had used MobiGuide was $127.2 \pm 68.6$ days for AF and $57.1 \pm 21.5$ days for GDM. Five of the AF patients and eight of the GDM patients switched context.

\subsubsection{Assessment of compliance to monitoring prescriptions and aggregated clinical parameter values}

The top part of Table 4 (rows R1-R4) presents a summary of the compliance of AF patients to monitoring plans as well as the aggregated values of the measurement results for the cohort patients. The prescribed number of measurements depends on the prescribed monitoring frequency, which for AF patients was once a day for ECG, and was either once or twice daily for BP, once a week for weight and once every two weeks for INR. The third column of Table 4 presents the mean compliance. The last column reports the aggregated measured values for the monitoring sessions.

Compliance of AF patients to the most important measurement (ECG, row R1) was "quite high" (mean compliance $\geq 0.65$, see row R1 in Table 4). Context did not affect reporting of drug non-compliance but semi-routine context had resulted in higher compliance for ECG monitoring (yet not statistically significant) and in lower compliance to BP (statistically significant) and INR monitoring plans, which we explain in the Discussion section.

\subsubsection{Assessment of compliance to ECG monitoring as a function of trigger type}

Rows R1.1-R1.3 of Table 4 present the results for ECG measurements as a function of different measurement triggers. The results are presented for each type of trigger that initiated the ECG session: system-initiated routine reminders, patient-initiated, and system initiated in response to patient's symptom reporting. In addition to compliance, these rows also reports the proportion of positive AF episodes detected by the algorithm.

The difference between compliance of patients to systeminitiated routine reminders and system-initiated triggers in response to patient's symptom reporting is not significant (Table 4, rows R1.1 and R1.3). In contrast, the proportion of AF+ episodes measured in system-initiated triggers in response to patient's symptom reporting (14/19, see row R1.3) is significantly higher than the proportion obtained for routine reminders measurements (88/729, see row R1.1), in which the Z-Score is 7.7259 and the $\mathrm{p}$-value $<0.0001$, or the proportion obtained by patient-initiated measurements (row R1.2. The Z-Score is 5.2473 and the p-value
$<0.0001)$. The proportion of AF+ episodes in patient-initiated measurements is also higher than that found in system-initiated requests, in response to symptom reporting (Z-Score is -2.4954 and the p-value is 0.01242).

\subsubsection{Compliance assessment for BG monitoring by GDM patients}

The top part of Table 5 presents similar data for GDM patients; all GDM patients were prescribed to measure the different data items presented in Table 5. Detailed results of each patient are shown in Appendix A. As can be seen in Table 5, GDM patients were highly compliant (mean compliance $\geq 0.8$ ) with measuring the most important health parameters (glycemia, ketonuria and BP).

\subsubsection{Comparison of the GDM cohort to a historical GDM cohort}

Table 6 provides the mean values of the variables measured in the MobiGuide's cohort and the historical cohort of patients, as well as the t-statistic and p-values. Significant differences are shown in bold.

\subsubsection{Assessment of compliance of patients to DSS recommendations}

As shown on the bottom part of Table 4 (rows R5-R7), AF patients had very high compliance to DSS recommendations (>0.9). The compliance of GDM patients to DSS recommendations is provided on the bottom part of Table 5. GDM patients' compliance to clinical recommendations was not high (0.31-0.5) for those recommendations that have been delivered at least 3 times, from which conclusions could be drawn.

\subsubsection{Assessment of compliance of clinicians to DSS recommendations}

The care providers' compliance to patient-specific recommendations is provided in Appendix A (Table A13 and A14). As Table A13 shows, cardioversion advice was delivered only for one patient, and here the clinicians were in full compliance. On the other hand, ECG summaries were produced about 8 times a week (demonstrating the rather high compliance to the daily ECG monitoring recommendations and the ability of patients to initiate additional ECG monitoring sessions at their discretion and as a response to reporting symptoms). The ratio of views (by clinicians) to ECG summary reports was 0.3 , but this is a low estimate because in each view several reports could be inspected. Clinicians reported to us that they viewed all of the reports, with the entire ECG signals, daily on their working days ( 5 days a week, not including vacations).

There are several technical reasons for the seemingly lower compliance of clinicians in the GDM domain (0-0.26, depending on recommendation, see Table A14), which we present in detail in the Discussion.

\subsection{Patient and care provider satisfaction results}

Tables B1 and B2 in Appendix B present the responses of patients and clinicians to the end-of-study questionnaires (answers provided on a Likert scale of 1 through 5). As shown in Table B1, both $\mathrm{AF}$ and GDM patients had positive sentiments toward the MobiGuide system. Half of the AF and more than two thirds (12/17) of the GDM patients provided positive ratings of 4 or 5 for confidence provided by the system. Almost all AF patients (6/7) and more than two thirds of the GDM patients liked the system's ability to adapt to context. $7 / 8$ of the AF patients reported that the system improved their peace of mind during travel and more than half of the AF patients reported that the system improved their interaction with clinicians (GDM patients were not asked these questions). All of the AF patients reported that they would recommend the system to others (total agreement of 5) and almost all of them (8/9) intend to use it in the future; GDM patients were a bit less enthusiastic, 
ranking their agreement to recommend the system to others at 4 or 5 and 12/14 patients reported their intention to use the system in the future. However, while most GDM patients (15/17) agreed that the system has not complicated their lives only a third of the AF patients agreed with this statement.

As for clinicians' attitudes, as shown in Table B2, all AF and GDM clinicians agreed (i.e., provided ratings of 4 or 5) that MobiGuide helps them in identifying priorities and increases patient safety via its data quality awareness (which prompts patients to re-enter data, repeat measurements, thus improving the recommendations delivered by the system that depend on data quality). All AF clinicians and two thirds of GDM clinicians agreed that the system makes it easier to manage patients.

\subsection{Quality of life of AF patients results}

Table 7 reports the results of the pre and post analysis of quality of life for AF, based on the EuroQoL and AFEQT questionnaires. The two Quality of life questionnaires seem to have somewhat conflicting results; while most patients reported an improvement in their quality of life in the EuroQoL questionnaire; most patients reported a deterioration in the AFEQT questionnaire. We suggest a possible explanation for these results in the Discussion. Detailed patient-by-patient results are shown in Appendix C.

\section{Summary and discussion}

The MobiGuide system is a clinical-guideline based, continuouscare, ubiquitous DSS, which is novel in its patient centrality, customization and personalization as well as distribution of decision support, and the semantic integration of multiple data sources. We have designed the system in a general way [12] to allow its implementation in different clinical domains and hospital settings. Design choices included the standard-based PHR [19] with its generic data insertion methods [19], the ability to connect with a wide range of sensors, and the ability to use the system with different smart phones.

In another study [13], we have focused on the patient usability evaluation. In this paper, we described the evaluation of MobiGuide in terms of medical compliance, satisfaction, and change in the patients' quality of life.

\subsection{Summary and discussion of the patients' compliance results}

Continuous monitoring of the most important health parameters (glycemia, ketonuria and BP for GDM patients) was performed at encouragingly high compliance rates by GDM patients. In general, the compliance of GDM patients to monitoring plans was higher than that of AF patients, which was however quite high for their most important measurement - ECG monitoring. One of the reasons may be that pregnant women are particularly concerned about their health due to possible risk to the baby as well as to themselves; their condition is new to them and temporary and they are thus highly motivated to keep in excellent health.

The compliance of AF patients to symptom-triggered ECG monitoring and system triggered monitoring reminders was similar (the difference is not statistically significant). However, the proportion of positive AF episodes ( $>10 \%$ of the time) was highest in response to patients' symptom reporting (0.74), and was still higher for patient-initiated sessions (0.19), compared to the lower proportion of positive AF episodes when the patients were reminded to perform an ECG (0.12). This issue touches at the heart of why one might need continuous monitoring at home, versus at the clinic or via a random one-day Holter monitoring. Given the sensitivity of the AF detection algorithm (0.64), we estimate that around 0.36 of the total ECGs performed had AF+ episodes, but had not been detected. Note that patients might have experienced AF symptoms during other times, but did not put on a belt. This confirms the value to clinicians of having monitoring sessions done by the patient at home (see also discussion of the value of home monitoring for patient diagnosis in Section 4.2), in order to understand the patient's perception of symptoms.

The compliance of AF patients in routine context to monitoring plans (that were prescribed to at least three patients, as results based on 1-2 patients are not meaningful) was quite high, in the range of $0.64-0.97$. The low compliance to INR reporting in semi-routine context is attributed to the fact that INR needs to be measured at the hospital while patients in semi-routine were on vacation, away from home. The low compliance to BP monitoring in semi-routine context is most likely because the monitoring frequency of BP was twice a day in semi-routine rather than the once daily in routine context. The higher compliance (though not statistically significant) of AF patients to ECG monitoring in semi-routine context could be explained by the fact that they were more concerned about this parameter when being away from home (the semi-routine context was associated with a vacation event for AF patients).

The compliance (of $\mathrm{AF}$ patients) to medication reminders seemed to be very high; however, it has been estimated indirectly, by assuming that patients had been compliant for all cases where they did not report medication non-compliance.

None of the patients were prescribed physical exercise. The care providers suggested to GDM patients to use the physical activity monitoring functionality of MobiGuide, yet they did not exercise often. This could be explained by the fact that to a large degree, patients in Spain still believe that exercise is not recommended during pregnancy. According to [38], women even decrease the amount of activity during pregnancy. Educational level is directly related to physical activity during pregnancy. Counseling on physical activity is usually a neglected area in maternal health promotion. Few nurses/doctors explain pregnant women that performing activity is safe and positive. Sociocultural factors have been shown to influence the impact of an ICT-based system for self-management of diabetes. There it was found that "the way nutrition is perceived and used in some cultures as a tool for socializing, affect significantly the final outcome of an ICT-based self-management intervention" [39]. These observation suggests that the system could be used to detect incorrect behaviors due to cultural heritage, and to try to correct them by sending encouragements to patients.

Most of the recommendations made by the MobiGuide DSS were reminders (for measurements or medications); a much smaller

Table 7

Quality of Life questionnaires results for AF patients.

\begin{tabular}{|c|c|c|c|c|c|}
\hline Questionnaire & Pre-MobiGuide & Post-MobiGuide & $\%$ patients who improved & $\%$ patients who remained & $\%$ patients who deteriorated \\
\hline \multicolumn{6}{|l|}{ EuroQoL } \\
\hline -Utility coefficient & $77.6 \pm 0.23$ & $78.4 \pm 0.23$ & $50 \%$ & $18 \%$ & $37.5 \%$ \\
\hline -Analogue score & $67.5 \pm 18.6$ & $80.1 \pm 13.0$ & $62.5 \%$ & $12.5 \%$ & $25 \%$ \\
\hline \multicolumn{6}{|l|}{ AFEQT } \\
\hline -Overall score & $73.0 \pm 14.9$ & $67.8 \pm 11.1$ & $25 \%$ & $12.5 \%$ & $62.5 \%$ \\
\hline -Treatment satisfaction & $72.3 \pm 18.7$ & $71.9 \pm 21.7$ & $37.5 \%$ & $37.5 \%$ & $25 \%$ \\
\hline
\end{tabular}


number of clinical recommendations were delivered by the system in response to detection of risky conditions, such as reporting of unacceptable symptoms and risky events in AF and of detection of abnormal BG or ketonuria values in GDM.

\subsection{Summary and discussion of clinical outcomes}

Although the number of patients in the study was too small to observe significant clinical outcomes (the study was, after all, mostly a feasibility study for the overall MobiGuide architecture and its functionality, and not a full-blown clinical trial), we were able to observe some preliminary indications that the MobiGuide system was able to help physicians reach medical decisions more quickly. In the domain of AF, the system allowed the care provider to change the diagnosis for two of the ten patients. For one patient, the clinicians noticed that the percent of time of being in an AF state was always close to $100 \%$, so the diagnosis changed from paroxysmal to permanent AF. For another patient, noticing that the system did not alert for any AF episodes, and looking at the actual ECG signals, the clinicians realized that indeed, the arrhythmia was not due to AF, but rather, due to a paroxysmal supraventricular tachycardia; this realization led to a correct treatment initiation. In the GDM domain, the system alerted the physician, in the case of two patients, that insulin should be started, before the weekly patient visit.

Moreover, the fact that the measurement data were available to the physicians via the system without needing to rely on the patients bringing in their monitoring devices and paper diaries had a great benefit. Since the clinicians knew the real data values, they felt that the decisions were made faster and were better; as they could review the results before the visits, the time spent reviewing the data was shorter.

So far, compliance to measurements has not been well studied in women with GDM, being mainly focused on appointments attendance [40]. Our study shows that, regarding BG measurement, the most relevant follow-up parameter, the mean compliance when using the system was 0.99 for following the monitoring plans (daily or twice weekly) and 0.87 for four measurements a day, corresponds to a very high degree of adherence. To compare the compliance of the MobiGuide cohort to that of the historical cohort, we calculated the compliance to at least 4 measurements a day as explained in the Methods section. The compliance of the MobiGuide cohort was significantly higher than that of the historical cohort ( 1.01 vs. 0.87 , with p-value of 0.0312 ), in spite of the different conditions of the two cohort (the MobiGuide patients received four reminders on each day, regarding which BG values were supposed to be measured, whereas the historical patients were instructed to measure "at least four measurements a day"). This high self-measurement compliance, accompanied by the relatively high compliance to ECG self-measurement $(0.65)$ in the AF group is especially encouraging, given two of the MobiGuide Project's main original objectives, namely, support for a patient-centered style of care that empowers patients, and containment of the increasing costs of chronic-patients care, by shifting the focus to a home-based one.

Thus, the evaluation's results have confirmed our expectations that risks would be identified earlier (e.g., early diagnosis of need for insulin), resulting in a more effective and efficient care process, leading to a high compliance to self-measurement and a good quality of health.

Table 6 also reports other interesting findings. First, compared with the MobiGuide cohort, the clinic-monitored cohort group had higher BP values (119.3/72.8 vs. 98.6/64.7), and a larger percentage of women on insulin (53.8 vs. 43.7). Second, the outcomes of pregnancy were comparable for the two groups, in terms of gestational week at delivery (38.7 vs. 39.5), birth weight (3.233 vs. 3.171), and percentile of newborn (50.8 vs. 46.2 ). There were more C-sections and fewer instrumental deliveries in the clinic-monitored historical cohort of patients, most likely reflecting changes in clinical practice. Furthermore, the MobiGuide patient group is too small for concluding such a clinical effect. However, future studies using the MobiGuide technology, comparing otherwise identical cohorts, might be able to determine whether some of the effect might be due to an improved BG control.

In the long run, we expect that a system such as MobiGuide could save multiple patient visits and hospitalizations, simply due to the patients being monitored at home, rather than at the clinic, and managed more closely and with a higher self compliance. However, this effect could not be systematically measured in our study. First, because the experimental study design asked the care providers to see the patients according to the normal visit schedule and not to cut down on visits even if the health state appears to be well controlled at home, according to the patient's data. Second, cutting down on hospitalizations for AF (GDM patients are not hospitalized) could not be detected in the brief nine months study, because hospitalizations normally occur not more than once a year. Nevertheless, the AF clinicians reported to us that several of the $\mathrm{AF}$ patients only had the enrollment visit and the end of study visit, and used the system from home for the whole duration of the study, thus supporting our vision for automated, home-based care. A related observation is that the mDSS was able to operate without the need for call backs to the Backend DSS for long periods of time: $14.8 \pm 7.3$ days for AF and $3.95 \pm 1.3$ days for GDM.

\subsection{Summary and discussion of patient satisfaction and quality of life}

It is a well known phenomenon that patients get tired of using (medical) applications after several weeks, especially for monitoring applications [41]. Yet, our results show that on average, GDM patients used the MobiGuide application for a mean of 2 months (and up to 3 months) and AF patients used it for 4.2 months (and up to 8.6 months). This behavior is also in line with the fact that only one of the twenty GDM patients who were recruited for the study and none of the ten AF patients had dropped out; and that three of the $\mathrm{AF}$ patients did not want to return the equipment at the end of the study and kept using the system while budget permitted, for several additional weeks. The different behavior exhibited for the use of the MobiGuide application shows that in high stakes domains, such as chronic care and maternity, patients have no trouble at all in monitoring themselves and in complying with recommendations for extended periods.

We used a questionnaire at the end of the pilot to obtain patients' perceptions about the system. AF and GDM patients agreed that the application was interesting and useful and expressed willingness to use it. They stated that they liked very much the system's ability to adapt to context. Overall, the sense of safety that the system has provided to the patients was its greatest asset. When interviewing the patients in person, many of them chose to spontaneously tell us about this quality of the system. One AF patient said, "With the system I feel the doctor by my side, as if he is hugging me". The fact that AF patients could initiate an ECG session might also have contributed to patient satisfaction, due to their ability and perception of having control over the system and over the patients' state.

The two Quality of life questionnaires seem to have had conflicting results; while most patients reported an improvement in their quality of life in the EuroQoL questionnaire; most patients reported a deterioration in the AFEQT questionnaire. Note however that (i) this is true only for the overall score, while results about treatment satisfaction are positive, and (ii) EuroQoL is a more general measure of quality of life, compared to AFEQT, which instead measures specifically the impact of the disease on the quality of life. Since 
$\mathrm{AF}$ is a chronic condition that normally worsens over time, it is not clear to what extent we can attribute these changes to the MobiGuide system. The correspondence between the EuroQoL and AFEQT scores could be evaluated for six patients. Good correspondence was seen in only four of them (see Appendix C).

Interpretation of the Quality of life results obtained by questionnaires should address the following considerations. First, even if the punctual values of the scores change, the level of the values is rather high for all of the patients. In the AFEQT questionnaire, these scores are computed by converting a number of answers given on a 1-7 Likert scale to a score that ranges from 0 to 100 , so variations of some units could be insignificant (e.g., an answer might range from "No difficulty at all" to "hardly any difficulty" or "A little difficulty"). In the literature, changes of up to 10 units were associated by patients with "small changes" in their perceived quality of life in a period of 3 months [42]. Another point that has to be considered is that the AFEQT questions are oriented at evaluating aspects that were not directly controllable by the MobiGuide system during the pilot (e.g. "how much difficulty have you had in doing any activity because you felt tired, fatigued or low energy?"). If any therapy change or intervention had been performed during the study, its effects could have been better assessed by this questionnaire.

\subsection{Summary and discussion of the clinicians' compliance and satisfaction}

AF clinicians complied with the cardioversion advice (which was given by the MobiGuide DSS to the one patient who met the eligibility criteria). The clinicians viewed the ECG summaries daily and found them useful. Most of the recommendations delivered to GDM clinicians concerned initiating therapy by insulin. For two out of the 18 women for which MobiGuide generated a recommendation to start insulin administration before the scheduled visit; the doctors complied with this recommendation. It would appear that the GDM physicians had a lower compliance to the MobiGuide system's recommendations; however, recommendations have often been declined because the recommendations were sent more than once, due to duplicate systems generated recommendations. Some recommendations were duplicated during the initial 2-3 weeks of the GDM pilot due to a repetition in blood glucose measurements downloaded to the system and it was then solved. In addition, in some cases, the physician noted the recommendation generated and considered alternative therapies (e.g., changing the diet rather than starting insulin therapy, an option that was not provided in the guideline) but she did not inform the system so the same recommendation was duplicated a few days later. A third reason was that some patients had started insulin therapy previously. Although the system allowed physicians to note the reason for non-compliance, this was not mandatory and was not recorded by the physicians, so we collected these reasons by interviewing the physicians.

Clinicians who have used the MobiGuide AF and GDM systems agreed that it made it easier to manage patients.

\subsection{Future research directions}

It is important to note that although the MobiGuide system introduces a new channel for communication and cooperation between patients and care providers, it may result in increased information flow, resulting in many challenges that need to be addressed in future research. These include designing technologies for mediating and facilitating patient-provider communication from the perspectives of human-computer interaction, computersupported cooperative work, public health, and medical practices [4].

However, the combined effect of remote management at the patient's local environment, and of enhanced quality of care, is expected to result in fewer visits and fewer hospitalizations for monitoring sessions that could be performed remotely in the patient's normal environment, while she is living her normal life, saving costs to the patients and to the overall healthcare system.

Our implementation of the MobiGuide system was not fully integrated into the hospitals' workflow management systems that manage resources and logistics. In another study [43], we describe our proof-of-concept implementation of a loosely-coupled approach to orchestrate the interaction between the MobiGuide Backend DSS and the Activiti Business Process Management (BPM) engine for five use cases arising from the AF MobiGuide implementation. We utilized the PHR of the MobiGuide project to implement the loosely coupled orchestration; changes in the PHR were detected by polling, while standards-based workflow documents orchestrated cross-enterprise therapeutic interventions. In particular, we describe the cardioversion process management. Future work is required to implement this framework within hospital setting.

The evaluation described in this paper provided proof of concept that a ubiquitous, distributed and personalized guideline-based DSS was well received by patients and clinicians and resulted in high levels of self-measurements by GDM patients and quite high levels by AF patients. However, the study was limited in its size, its duration in the case of $\mathrm{AF}$ patients, and the lack of baseline compliance rates (no baseline rates for AF patients' usage of the sensors without usage of the full MobiGuide system, and baseline rates only for BG measurements for GDM patients). Future clinical trials should be conducted in order to draw valid conclusions regarding the system's contribution to improvement in care quality and outcomes.

\section{Conclusions}

MobiGuide is an interactive guideline-based DSS for patientcentered care designed to enhance patient engagement. MobiGuide implements several novel ideas for personalized patient guidance to patients and to their care providers, while maintaining patient safety, and is based on evidence-based clinical guidelines as well as a novel distributed service-oriented architecture. Its feasibility was demonstrated by a working prototype that was successfully evaluated in a preliminary fashion for the AF domain in a hospital in Italy and for GDM with and without hypertension in a hospital in Spain. The evaluation has shown high compliance of GDM patients and quite high compliance of AF patients, to clinical guideline recommendations, and an increase in-patient and care provider satisfaction, as well as an impact on clinicians' diagnoses and therapy changes. The combined effect of remote management at the patient's local environment, and of enhanced quality of care, carries a potential future promise for significant cost saving, due to both a lower rate of complications and hospitalizations, as well as fewer clinic visits for monitoring purposes; we suggest that future studies focus on that promise.

\section{Conflict of interest}

None.

\section{Authors' contributions}

Mor Peleg was the project coordinator, leader of the requirement analysis phase, took part in the development of the PHR, knowledge-data ontology mapper, and psychosocial and demographic context elicitation. She analyzed the AF compliance evaluation results and wrote this paper. Yuval Shahar led the development of decision-support distribution and temporal mediation, and conceptualized the idea of CIG customization. He also helped 


\section{Summary points}

What was already known on the topic

- Computer-interpretable guideline (CIG) based DSSs can provide patient-specific evidence-based recommendations to care providers at the point of care during patient encounters.

- CIG-based decision support systems can impact clinicians behavior more effectively than the respective clinical practice guidelines on which they have been based.

What this study added to our knowledge

- Customization of CIGs to psychosocial and demographic context and preferences of patients can provide personalized decision support, which patients like very much, valuing the sense of safety that the system provides to them. Patientcentric, distributed DSS that is extended to mobile devices contributes to easy management of patients.

- The distributed and personalized MobiGuide DSS, in both the atrial fibrillation and gestational diabetes mellitus domains, resulted in a high self-measurement compliance by the patients.

in writing significant parts of this paper. Silvana Quaglini led the formalization of shared decision making, system testing, and the evaluation study design. She also helped in writing significant parts of this paper. Tom Broens and Daniel Knoppel led and coordinated system development and sensor integration. Adi Fux developed the ontology of psychosocial and demographic context, together with Pnina Soffer and Mor Peleg, and also defined the mappings of the CIGs concepts to the PHR. Gema García-Sáez led the knowledge acquisition of the GDM guideline and analyzed the evaluation data for the GDM domain. Ayelet Goldstein carried out formalization and customization of the AF and GDM guidelines. Arturo González-Ferrer designed the HL7 virtual medical record-based PHR and helped in mapping the CIGs to the PHR. Hermie Hermens led the University of Twente team. Elena Hernando led the physical activity detection algorithm development and oversaw the development of the mobile GUI and GDM data analysis. Val Jones, together with Nick Fung and Boris van Schooten developed the mDSS and contributed to developing the mechanism for DSS distribution. Guy Klebanov developed the knowledge-data ontology mapper and defined XQueries for data retrieval. Denis Klimov developed the data mediator. Nekane Larburu defined the technological context and quality of data broker. Carlos Marcos developed the PHR and data integrator. Iñaki Martínez-Sarriegui developed the mobile GUI. Carlo Napolitano and Roxana Budasu were the AF clinical experts who helped to define and carried out the AF study with patients. Mercedes Rigla and Belén Pons were the GDM clinical experts who helped to define and carried out the GDM study with patients. Àngels Pallàs represented the patient's advocacy. Angel Palomares led security and privacy. Enea Parimbelli and Lucia Sacchi led the development of the care provider GUI and carried out a large part of the evaluation results' analysis. Erez Shalom led the development of the distributed DSS and carried out a large part of the evaluation results' analysis.

\section{Acknowledgement}

This paper has received funding from the European Unionís Seventh Framework Programme for research, technological development and demonstration under grant agreement no. 287811.

\section{Appendix A. Detailed results}

Tables A1-A12

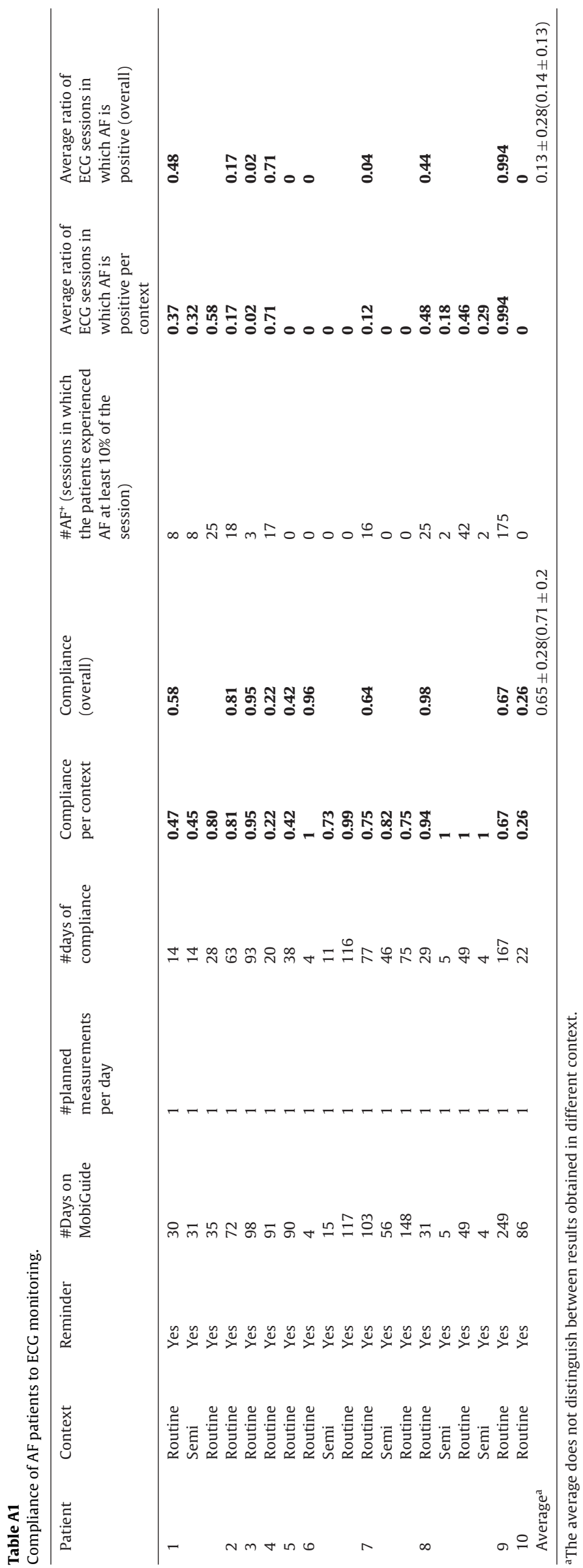


Table A2

Compliance of AF patients to BP monitoring.

\begin{tabular}{|c|c|c|c|c|c|c|c|c|c|}
\hline Patient & $\begin{array}{l}\text { Has } \\
\text { hypertension? }\end{array}$ & Context & Reminder & $\begin{array}{l}\text { \#Days on } \\
\text { MobiGuide }\end{array}$ & $\begin{array}{l}\text { \#planned measurements } \\
\text { per day/week }\end{array}$ & $\begin{array}{l}\text { \#planned } \\
\text { measurements }\end{array}$ & $\begin{array}{l}\text { \#times of compliance } \\
\text { (partial compliance }^{\mathrm{a}} \text { ) }\end{array}$ & $\begin{array}{l}\text { Compliance } \\
\text { (partial) }\end{array}$ & $\begin{array}{l}\text { Average } \\
\text { BP }\end{array}$ \\
\hline \multirow[t]{4}{*}{1} & \multirow[t]{4}{*}{ No } & \multirow[t]{2}{*}{ Routine } & No & 18 & 1/week & 2.6 & 1 & 0.06 & $130 / 80$ \\
\hline & & & Yes & 12 & 1/week & $1.7^{\mathrm{b}}$ & 0 & $0^{\mathrm{a}}$ & NA \\
\hline & & Semi & Yes & 31 & 1/week & 4.4 & 1 & 0 & $115 / 87$ \\
\hline & & Routine & Yes & 35 & 1/week & 5 & 1 & 0.03 & $118 / 89$ \\
\hline \multirow[t]{2}{*}{2} & \multirow[t]{2}{*}{ Yes } & \multirow[t]{2}{*}{ Routine } & No & 68 & $1 /$ day & 68 & 1 & 0.02 & $130 / 80$ \\
\hline & & & Yes & 10 & $1 /$ day & 10 & 0 & 0 & NA \\
\hline \multirow[t]{2}{*}{3} & \multirow[t]{2}{*}{ No } & \multirow[t]{2}{*}{ Routine } & No & 54 & 1/week & 7.7 & 22 & 2.75 & $106 / 66$ \\
\hline & & & Yes & 34 & 1/week & 4.9 & 32 & 6.6 & $105 / 67$ \\
\hline \multirow[t]{2}{*}{4} & \multirow[t]{2}{*}{ No } & \multirow[t]{2}{*}{ Routine } & No & 33 & 1/week & 4.7 & 1 & 0.21 & $90 / 60$ \\
\hline & & & Yes & 58 & 1/week & 8.3 & 2 & 0.24 & $130 / 60$ \\
\hline 5 & No & Routine & Yes & 90 & 1/week & 12.9 & 3 & 0.23 & $107 / 69$ \\
\hline \multirow[t]{2}{*}{7} & \multirow[t]{2}{*}{ Yes } & Routine & No & 45 & $1 /$ day & 45 & 14 & 0.31 & $120 / 74$ \\
\hline & & Semi & Yes & 20 & 2/day & 40 & $1(11)$ & $0.05(0.55)$ & $130 / 80$ \\
\hline \multirow[t]{3}{*}{8} & \multirow[t]{3}{*}{ No } & Routine & No & 39 & 1/week & 5.6 & 4 & 0.72 & $116 / 58$ \\
\hline & & Routine & Yes & 5 & 1/week & $0.7^{\mathrm{b}}$ & 1 & $1^{\mathrm{a}}$ & $112 / 59$ \\
\hline & & Semi & Yes & 4 & 1/week & $0.6^{\mathrm{b}}$ & 0 & $0^{\mathrm{a}}$ & NA \\
\hline 9 & Yes & Routine & Yes & 249 & $1 /$ day & 249 & 56 & 0.23 & $107 / 56$ \\
\hline
\end{tabular}

a Partial compliance = days on which BP was measured once instead of twice in semi-routine context for hypertensive patients.

b If the planned number of measurements is $\leq 2$ then these rows were not taken into consideration in the mean value.

Table A3

Compliance of AF patients to INR monitoring

\begin{tabular}{|c|c|c|c|c|c|c|c|}
\hline Patient & Context & Reminder & \#Days on MobiGuide & \#planned measurements & \#days of compliance & Compliance & INR \\
\hline \multirow[t]{3}{*}{7} & Routine & No & 103 & 7.4 & 5 & 0.71 & 2.24 \\
\hline & Semi & Yes & 56 & 4 & 0 & 0 & NA \\
\hline & Routine & Yes & 100 & 7.1 & 4 & 0.57 & 2.2 \\
\hline
\end{tabular}

Table A4

Compliance of AF patients to weight monitoring.

\begin{tabular}{|c|c|c|c|c|c|c|c|}
\hline Patient & Context & Reminder & \#Days on MobiGuide & \#planned measurements & \#days of compliance & Compliance & Weight (Kg) \\
\hline \multirow[t]{2}{*}{2} & Routine & No & 68 & 9.7 & 2 & 0.22 & 87 \\
\hline & & Yes & 10 & $1.4^{*}$ & 0 & 0 & NA \\
\hline 5 & Routine & Yes & 90 & 12.9 & 1 & 0.08 & 90 \\
\hline
\end{tabular}

Table A5

Drug non-compliance reporting by AF patients.

\begin{tabular}{|c|c|c|c|c|c|}
\hline Patient & Context & Reminder & \#Days on MobiGuide & \#non compliances & Type non compliance \\
\hline \multirow[t]{3}{*}{1} & Routine & Yes & 12 & 1 & Forgot \\
\hline & Semi & Yes & 31 & 2 & Forgot \\
\hline & Routine & Yes & 35 & 3 & Forgot \\
\hline 4 & Routine & Yes & 91 & 0 & NA \\
\hline 5 & Routine & Yes & 90 & 0 & NA \\
\hline \multirow[t]{3}{*}{6} & Routine & Yes & 4 & 0 & \\
\hline & Semi & Yes & 15 & 1 & Unavailable (1) \\
\hline & Routine & Yes & 107 & 1 & Unavailable (1) \\
\hline \multirow[t]{3}{*}{7} & Routine & Yes & 103 & 4 & \\
\hline & Semi & Yes & 56 & 2 & \\
\hline & Routine & Yes & 148 & 1 & Side-effects(1) \\
\hline \multirow[t]{4}{*}{8} & Routine & Yes & 31 & 1 & Unavailable (1) \\
\hline & Semi & Yes & 5 & 1 & Unavailable (1) \\
\hline & Routine & Yes & 49 & 4 & Unavailable (2), Forgot (2) \\
\hline & Semi & Yes & 4 & 0 & \\
\hline
\end{tabular}

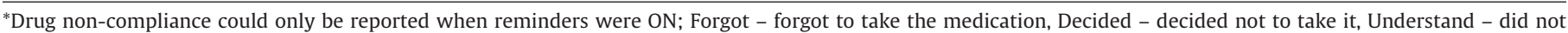

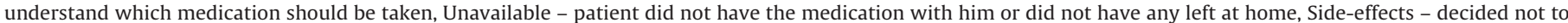
take it because of side effects experienced with the medication. 
Table A6

AF Patients' compliance to recommendations.

\begin{tabular}{|c|c|c|c|c|}
\hline Patient & $\begin{array}{l}\text { Days on } \\
\text { MobiGuide }\end{array}$ & $\begin{array}{l}\text { Talk to your doctor about changing } \\
\text { anticoagulation therapy due to the risky } \\
\text { event you reported }(R)\end{array}$ & $\begin{array}{l}\text { Keep taking anticoagulant } \\
\text { before cardioversion }(R)\end{array}$ & $\begin{array}{l}\text { Technical } \\
\text { recommendations }(\mathrm{T})\end{array}$ \\
\hline 1 & 96 & NA & NA & 43 \\
\hline 2 & 78 & 1 & NA & 4 \\
\hline 3 & 98 & NA & NA & 6 \\
\hline 4 & 91 & NA & NA & \# \\
\hline 5 & 90 & NA & NA & 33 \\
\hline 6 & 136 & NA & $1 ; 1$ & 7 \\
\hline 7 & 259 & NA & NA & 41 \\
\hline 8 & 89 & NA & NA & 4 \\
\hline 9 & 249 & NA & NA & 39 \\
\hline 10 & 86 & NA & NA & 28 \\
\hline Mean and Stdev(Mode \& \%) & $127.2 \pm 68.6$ days $\cong 18 \pm 10$ week & $(0 ; 90 \%)$ & (0; 90\%) compliance: 1 & Monthly average: $5.55 \pm 4.4$ \\
\hline
\end{tabular}

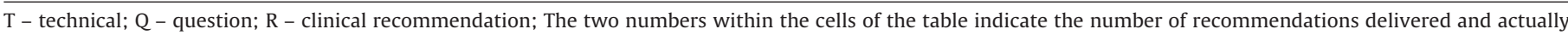
followed (number not always available); \# - mobile log was not available for this patient.

Table A7

Patient-by-patient results summary for AF patients.

\begin{tabular}{|c|c|c|c|c|c|c|c|c|c|c|c|c|c|}
\hline Patient & $\begin{array}{l}\text { Context } \\
\text { switches }\end{array}$ & $\begin{array}{l}\text { ECG } \\
\text { comp }\end{array}$ & $\mathrm{AF}+$ & $\begin{array}{l}\text { BP } \\
\text { comp }\end{array}$ & BP val & $\begin{array}{l}\text { INR } \\
\text { comp }\end{array}$ & INR & $\begin{array}{l}\text { Weight } \\
\text { comp }\end{array}$ & Weight & $\begin{array}{l}\text { Medication } \\
\text { compliance }\end{array}$ & Quality of life & $\begin{array}{l}\text { Safety } \\
\text { confidence }\end{array}$ & $\begin{array}{l}\text { Willing to } \\
\text { use }\end{array}$ \\
\hline 1 & $\mathrm{Y}$ & $\mathrm{H}$ & $\mathrm{M}(\mathrm{L})$ & $\mathrm{L}$ & $\sqrt{ }$ & & & & & $\mathrm{H}$ & dec; dec & 4 & $\mathrm{Y}$ \\
\hline 2 & $\mathrm{~N}$ & $\mathrm{H}$ & $\mathrm{L}$ & $\mathrm{L}$ & $\sqrt{ }$ & & & $\mathrm{L}$ & $\sqrt{ }$ & & Inc; \# & \# & \# \\
\hline 3 & $\mathrm{~N}$ & $\mathrm{H}$ & $\mathrm{L}$ & $\mathrm{H}$ & $\sqrt{ }$ & & & & & & unc; \# & 4 & $\mathrm{Y}$ \\
\hline 4 & $\mathrm{~N}$ & $\mathrm{~L}$ & $\mathrm{H}$ & $\mathrm{L}$ & $\sqrt{ }$ & & & & & $\mathrm{H}$ & \#; dec & 4 & $\mathrm{Y}$ \\
\hline 5 & $\mathrm{~N}$ & $\mathrm{~L}$ & $\mathrm{~L}$ & $\mathrm{~L}$ & $\sqrt{ }$ & & & $\mathrm{L}$ & $\sqrt{ }$ & $\mathrm{H}$ & inc; inc & 4 & $\mathrm{Y}$ \\
\hline 6 & $\mathrm{Y}$ & $\mathrm{H}$ & $\mathrm{L}$ & $\mathrm{L}$ & $\sqrt{ }$ & & & & & $\mathrm{H}$ & inc; inc & 3 & $\mathrm{Y}$ \\
\hline 7 & $\mathrm{Y}$ & $\mathrm{H}$ & $\mathrm{L}$ & $\mathrm{L}$ & $\sqrt{ }$ & L-M & $\sqrt{ }$ & & & $\mathrm{H}$ & dec; dec & 5 & $\mathrm{Y}$ \\
\hline 8 & $\mathrm{Y}$ & $\mathrm{H}$ & $\mathrm{M}(\mathrm{L})$ & $\mathrm{H}(\mathrm{L})$ & $\sqrt{ }$ & & & & & $\mathrm{H}$ & inc; dec & 4 & $\mathrm{~N}$ \\
\hline 9 & $\mathrm{~N}$ & M & $\mathrm{H}$ & $\mathrm{L}$ & $\sqrt{ }$ & & & & & & inc; unc & \# & $\mathrm{Y}$ \\
\hline 10 & $\mathrm{~N}$ & $\mathrm{M}$ & $\mathrm{L}$ & $\mathrm{L}$ & $\sqrt{ }$ & & & & & & \#; dec & 4 & $\mathrm{Y}$ \\
\hline Mode an & N 60\% & H $50 \%$ & L 60\% & L 78\% & $\sqrt{ }$ & & & $\mathrm{L}$ & $\sqrt{ }$ & $\mathrm{H}$ & inconclusive & $475 \%$ & Y 89\% \\
\hline
\end{tabular}

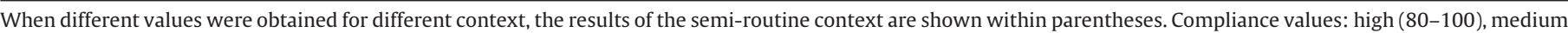

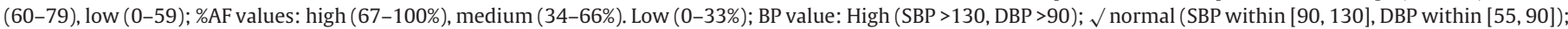

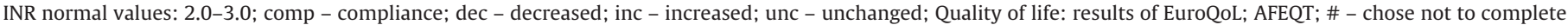
the questionnaire.

Table A8

Glycemia monitoring compliance reporting by GDM patients.

\begin{tabular}{|c|c|c|c|c|c|c|c|c|}
\hline Patient & $\begin{array}{l}\text { BG Monitoring } \\
\text { plan }\end{array}$ & Reminder & $\begin{array}{l}\text { \#Days on } \\
\text { monitoring plan }\end{array}$ & \#Total BG & $\begin{array}{l}\text { Days } \\
\# B G>=4\end{array}$ & $\begin{array}{l}\text { Average \#BG } \\
\text { per day }\end{array}$ & $\begin{array}{l}\text { Compliance to } 4 \mathrm{BG} \\
\text { per day }\end{array}$ & $\begin{array}{l}\text { Compliance to BG } \\
\text { monitoring plan }\end{array}$ \\
\hline P1 & Daily & Yes & 36 & 162 & 30 & 4.50 & 0.83 & 1.00 \\
\hline P2 & Daily & Yes & 34 & 145 & 27 & 4.26 & 0.90 & 0.88 \\
\hline P3 & Daily & Yes & 28 & 107 & 17 & 3.82 & 0.61 & 1.00 \\
\hline P4 & Daily & Yes & 64 & 294 & 59 & 4.59 & 0.92 & 0.98 \\
\hline P5 & Daily & Yes & 33 & 129 & 27 & 3.91 & 0.82 & 1.00 \\
\hline P5 & Twice a week & Yes & 18 & 71 & 13 & 4.46 & 1.00 & 1.00 \\
\hline P6 & Daily & Yes & 47 & 182 & 41 & 3.87 & 0.87 & 1.00 \\
\hline P7 & Daily & Yes & 90 & 411 & 83 & 4.57 & 0.93 & 0.98 \\
\hline P8 & Daily & Yes & 61 & 222 & 39 & 3.64 & 0.64 & 1.00 \\
\hline P8 & Twice a week & Yes & 31 & 101 & 15 & 4.00 & 1.00 & 1.00 \\
\hline P9 & Daily & Yes & 77 & 300 & 56 & 3.90 & 0.73 & 1.00 \\
\hline P10 & Daily & Yes & 36 & 142 & 29 & 3.94 & 0.81 & 0.97 \\
\hline P12 & Daily & Yes & 49 & 204 & 37 & 4.16 & 0.77 & 0.98 \\
\hline P13 & Daily & Yes & 57 & 225 & 43 & 3.95 & 0.75 & 1.00 \\
\hline P14 & Daily & Yes & 72 & 330 & 70 & 4.58 & 0.97 & 1.00 \\
\hline P15 & Daily & Yes & 20 & 81 & 18 & 4.05 & 0.90 & 0.95 \\
\hline P16 & Daily & Yes & 91 & 360 & 89 & 3.96 & 0.98 & 0.99 \\
\hline P17 & Daily & Yes & 53 & 213 & 49 & 4.02 & 0.92 & 1.00 \\
\hline P18 & Daily & Yes & 51 & 205 & 50 & 4.02 & 0.98 & 1.00 \\
\hline P19 & Daily & Yes & 73 & 315 & 70 & 4.32 & 0.96 & 1.00 \\
\hline P20 & Daily & Yes & 65 & 265 & 59 & 4.08 & 0.91 & 1.00 \\
\hline
\end{tabular}

a Patient's compliance to measure 4 or more BG values per day (considering all the days when at least 1 measurement was done).

b Patient's compliance to follow BG monitoring plan (i.e., monitor BG every day or twice a week).

Table A9

BP monitoring compliance reporting by GDM patients.

\begin{tabular}{|c|c|c|c|c|c|c|c|c|c|c|}
\hline \multirow[t]{2}{*}{ Patient } & \multirow{2}{*}{$\begin{array}{l}\text { BP Monitoring } \\
\text { plan }\end{array}$} & \multirow[t]{2}{*}{ Reminder } & \multirow{2}{*}{$\begin{array}{l}\text { \#Weeks on } \\
\text { monitoring plan }\end{array}$} & \multirow[t]{2}{*}{ \#Total BP } & \multirow{2}{*}{$\begin{array}{l}\text { \#planned } \\
\text { measurements }\end{array}$} & \multicolumn{3}{|l|}{ \# Weeks } & \multirow{2}{*}{$\begin{array}{l}\text { Compliance to } \\
\text { monitoring plan }\end{array}$} & \multirow{2}{*}{$\begin{array}{l}\text { \#times entered } \\
\text { manually }\end{array}$} \\
\hline & & & & & & $\# \mathrm{BP}>=2$ & $\# \mathrm{BP}=1$ & $\# \mathrm{BP}=0$ & & \\
\hline P1 & Twice a week & No & 2 & 3 & 2.86 & 1 & 1 & 0 & 0.5 & \\
\hline P1 & Once a week & No & 3 & 4 & 3.71 & 1 & 1 & 1 & 0.7 & \\
\hline
\end{tabular}


Table A9 (Continued)

\begin{tabular}{|c|c|c|c|c|c|c|c|c|c|c|}
\hline \multirow[t]{2}{*}{ Patient } & \multirow{2}{*}{$\begin{array}{l}\text { BP Monitoring } \\
\text { plan }\end{array}$} & \multirow[t]{2}{*}{ Reminder } & \multirow{2}{*}{$\begin{array}{l}\text { \#Weeks on } \\
\text { monitoring plan }\end{array}$} & \multirow[t]{2}{*}{ \#Total BP } & \multirow{2}{*}{$\begin{array}{l}\text { \#planned } \\
\text { measurements }\end{array}$} & \multicolumn{3}{|l|}{ \# Weeks } & \multirow{2}{*}{$\begin{array}{l}\text { Compliance to } \\
\text { monitoring plan }\end{array}$} & \multirow{2}{*}{$\begin{array}{l}\text { \#times entered } \\
\text { manually }\end{array}$} \\
\hline & & & & & & $\# \mathrm{BP}>=2$ & $\# \mathrm{BP}=1$ & $\# \mathrm{BP}=0$ & & \\
\hline P2 & Twice a week & No & 3 & 6 & 6.29 & 3 & 0 & 0 & 1.0 & 7 \\
\hline P2 & Once a week & No & 2 & 1 & 1.71 & 0 & 2 & 0 & $1.0^{\mathrm{a}}$ & \\
\hline P3 & Once a week & No & 4 & 3 & 3.86 & 2 & 0 & 2 & 0.5 & 1 \\
\hline P4 & Twice a week & No & 4 & 11 & 7.71 & 3 & 1 & 0 & 0.8 & \\
\hline P4 & Once a week & No & 5 & 7 & 5.29 & 2 & 2 & 1 & 0.8 & \\
\hline P5 & Twice a week & No & 1 & 3 & 2.57 & 1 & 0 & 0 & 1.0 & \\
\hline P5 & Once a week & No & 6 & 13 & 6.00 & 6 & 0 & 0 & 1.0 & \\
\hline P6 & Twice a week & No & 2 & 3 & 3.14 & 2 & 0 & 0 & 1.0 & \\
\hline P6 & Once a week & No & 5 & 3 & 5.14 & 1 & 0 & 4 & 0.2 & \\
\hline P7 & Twice a week & No & 4 & 18 & 8.00 & 4 & 0 & 0 & 1.0 & 7 \\
\hline P7 & Once a week & No & 9 & 18 & 8.86 & 7 & 2 & 0 & 1.0 & \\
\hline P8 & Twice a week & No & 5 & 28 & 10.00 & 5 & 0 & 0 & 1.0 & 2 \\
\hline P8 & Once a week & No & 8 & 4 & 8.14 & 2 & 0 & 6 & 0.3 & \\
\hline P9 & Twice a week & No & 1 & 3 & 2.29 & 1 & 0 & 0 & 1.0 & \\
\hline P9 & Once a week & No & 10 & 0 & 9.86 & 0 & 1 & 9 & 0.1 & \\
\hline P10 & Twice a week & No & 3 & 5 & 6.29 & 2 & 1 & 0 & 0.7 & 1 \\
\hline P10 & Once a week & No & 2 & 0 & 2.00 & 0 & 0 & 2 & 0.0 & \\
\hline P12 & Twice a week & No & 2 & 4 & 3.43 & 2 & 0 & 0 & 1.0 & \\
\hline P12 & Once a week & No & 5 & 8 & 5.29 & 2 & 2 & 1 & 0.8 & \\
\hline P13 & Twice a week & No & 3 & 7 & 5.71 & 2 & 1 & 0 & 0.7 & 6 \\
\hline P13 & Once a week & No & 5 & 6 & 5.29 & 1 & 4 & 0 & 1.0 & \\
\hline P14 & Twice a week & No & 2 & 14 & 3.43 & 2 & 0 & 0 & 1.0 & 21 \\
\hline P14 & Once a week & No & 8 & 16 & 8.57 & 3 & 5 & 0 & 1.0 & \\
\hline P15 & Twice a week & No & 3 & 32 & 5.71 & 3 & 0 & 0 & 1.0 & 5 \\
\hline P16 & Twice a week & No & 4 & 9 & 8.29 & 4 & 0 & 0 & 1.0 & 1 \\
\hline P16 & Once a week & No & 9 & 17 & 8.86 & 8 & 1 & 0 & 1.0 & \\
\hline P17 & Twice a week & No & 3 & 9 & 6.86 & 3 & 0 & 0 & 1.0 & \\
\hline P17 & Once a week & No & 4 & 7 & 4.14 & 2 & 2 & 0 & 1.0 & \\
\hline P18 & Twice a week & No & 2 & 3 & 2.86 & 2 & 0 & 0 & 1.0 & \\
\hline P18 & Once a week & No & 4 & 6 & 5.86 & 1 & 3 & 0 & 1.0 & \\
\hline P19 & Twice a week & No & 10 & 80 & 20.86 & 9 & 0 & 1 & 0.9 & \\
\hline P20 & Twice a week & No & 1 & 2 & 1.43 & 1 & 0 & 0 & $1.0^{\mathrm{a}}$ & \\
\hline P20 & Once a week & No & 8 & 7 & 8.57 & 2 & 2 & 4 & 0.5 & \\
\hline
\end{tabular}

a Data not used to compute the mean compliance.

Table A10

Ketonuria monitoring compliance reporting by GDM patients.

\begin{tabular}{|c|c|c|c|c|c|c|}
\hline Patient & Ketonuria Monitoring plan & Reminder & \#Days on monitoring plan & \#Total Ketonuria & \#planned measurements & Compliance to monitoring plan \\
\hline P1 & Daily & Yes & 15 & 12 & 15.00 & 0.8 \\
\hline P1 & Twice a week & Yes & 21 & 14 & 6.00 & 1 \\
\hline P2 & Daily & Yes & 34 & 32 & 34.00 & 0.94 \\
\hline P3 & Daily & Yes & 4 & 4 & 4.00 & 1 \\
\hline P3 & Twice a week & Yes & 24 & 25 & 6.86 & 1 \\
\hline P4 & Daily & Yes & 57 & 39 & 57.00 & 1 \\
\hline P4 & Twice a week & Yes & 7 & 7 & 2.00 & 1 \\
\hline P5 & Daily & Yes & 51 & 51 & 51.00 & 1 \\
\hline P6 & Daily & Yes & 16 & 14 & 16.00 & 1 \\
\hline P6 & Twice a week & Yes & 31 & 16 & 8.86 & 1 \\
\hline P7 & Daily & Yes & 9 & 12 & 9.00 & 0.89 \\
\hline P7 & Twice a week & Yes & 81 & 61 & 23.14 & 1 \\
\hline P8 & Daily & Yes & 15 & 13 & 15.00 & 1 \\
\hline P8 & Twice a week & Yes & 77 & 77 & 22.00 & 1 \\
\hline P9 & Daily & Yes & 18 & 17 & 18.00 & 1 \\
\hline P9 & Twice a week & Yes & 59 & 60 & 16.86 & 1 \\
\hline P10 & Daily & Yes & 19 & 19 & 19.00 & 0.95 \\
\hline P10 & Twice a week & Yes & 17 & 17 & 4.86 & 1 \\
\hline P12 & Daily & Yes & 13 & 12 & 13.00 & 0.92 \\
\hline P12 & Twice a week & Yes & 36 & 36 & 10.29 & 1 \\
\hline P13 & Daily & Yes & 18 & 18 & 18.00 & 0.94 \\
\hline P13 & Twice a week & Yes & 39 & 39 & 11.14 & 1 \\
\hline P14 & Daily & Yes & 36 & 29 & 36.00 & 1 \\
\hline P14 & Twice a week & Yes & 37 & 35 & 10.57 & 1 \\
\hline P15 & Daily & Yes & 20 & 17 & 20.00 & 0.94 \\
\hline P16 & Daily & Yes & 19 & 17 & 19.31 & 1 \\
\hline P16 & Twice a week & Yes & 73 & 71 & 20.77 & 1 \\
\hline P17 & Daily & Yes & 5 & 5 & 5.48 & 1 \\
\hline P17 & Twice a week & Yes & 49 & 22 & 13.86 & 1 \\
\hline P18 & Daily & Yes & 13 & 12 & 13.39 & 1 \\
\hline P18 & Twice a week & Yes & 39 & 36 & 11.03 & 1 \\
\hline P19 & Daily & Yes & 17 & 15 & 17.33 & 1 \\
\hline P19 & Twice a week & Yes & 57 & 52 & 16.19 & 1 \\
\hline P20 & Daily & Yes & 13 & 12 & 13.43 & 0.82 \\
\hline P20 & Twice a week & Yes & 53 & 45 & 15.02 & 1 \\
\hline
\end{tabular}


Table A11

GDM Patients' compliance to recommendations/questions asked.

\begin{tabular}{|c|c|c|c|c|c|c|c|}
\hline Patient & $\begin{array}{l}\text { Days on } \\
\text { MobiGuide }\end{array}$ & $\begin{array}{l}\text { Technical } \\
\text { Recommendations (T) }\end{array}$ & $\begin{array}{l}\text { High BG ( } 2 \text { abnormal per } \\
\text { week). Did you eat more } \\
\text { than you should? (Q) }\end{array}$ & $\begin{array}{l}2 \text { high BG in a week. visit } \\
\text { your doctor* }(\mathrm{R})\end{array}$ & $\begin{array}{l}\text { Have you been eating your } \\
\text { prescribed amount of } \\
\text { carbohydrates? (ketonuria) (Q) }\end{array}$ & $\begin{array}{l}\text { Ketonuria has been positive; } \\
\text { please increase your } \\
\text { carbohydrates @bedtime (R) }\end{array}$ & $\begin{array}{l}\text { Ketonuria has been positive } \\
\text { again. You should visit your } \\
\text { doctor in the next few days ( } R\end{array}$ \\
\hline 1 & 42 & 12 & $5 ; 0$ & $1 ; 1$ & 0 & 0 & 0 \\
\hline 2 & 48 & 1 & $3 ; 0$ & 0 & 2 & 0 & 0 \\
\hline 3 & 35 & 12 & $2 ; 1$ & 0 & 0 & 0 & 0 \\
\hline 4 & 63 & 21 & $3 ; 0$ & 0 & 0 & 0 & 0 \\
\hline 5 & 52 & 6 & $1 ; 1$ & 0 & $2 ; 2$ & $1 ; 1$ & $1 ; 0$ \\
\hline 6 & 46 & 0 & $1 ; 1$ & 0 & 0 & 0 & 0 \\
\hline 7 & 91 & 48 & $3 ; 2$ & 1:0 & 0 & 0 & 0 \\
\hline 8 & 93 & 14 & $7 ; 4$ & 0 & 0 & 0 & 0 \\
\hline 9 & 78 & 9 & $5 ; 0$ & 0 & 0 & 0 & 0 \\
\hline 10 & 36 & 4 & $1 ; 0$ & 0 & 0 & 0 & 0 \\
\hline 12 & 50 & 10 & $2 ; 1$ & 0 & 0 & 0 & 0 \\
\hline 13 & 56 & 0 & $2 ; 0$ & 1:0 & 0 & 0 & 0 \\
\hline 14 & 71 & 25 & $1 ; 1$ & 0 & $1 ; 0$ & 0 & 0 \\
\hline 15 & 19 & 0 & $1 ; 1$ & 0 & $1 ; 1$ & 0 & 0 \\
\hline 16 & 90 & 16 & $2 ; 0$ & $1: 1$ & 0 & 0 & 0 \\
\hline 17 & 59 & 1 & $1 ; 0$ & 0 & 0 & 0 & 0 \\
\hline 18 & 50 & 4 & $3 ; 1$ & 0 & 0 & 0 & 0 \\
\hline 19 & 72 & - & $4 ; 1$ & 1:0 & 0 & 0 & 0 \\
\hline 20 & 64 & 13 & $4 ; 2$ & $1: 0$ & 0 & 0 & 0 \\
\hline $\begin{array}{l}\text { Mean and Std. } \\
\text { (Mode \& \%) }\end{array}$ & $\begin{array}{l}58.68 \pm 20.22 \text { daa } \\
\cong 8 \pm 3 \text { week }\end{array}$ & $\begin{array}{l}\text { Monthly } \\
\text { average: } 4.7 \pm 4.5\end{array}$ & $\begin{array}{l}\text { Compliance: } \\
0.31\end{array}$ & $\begin{array}{l}\text { Compliance: } \\
0.5\end{array}$ & $\begin{array}{l}\text { Compliance: } \\
0.5\end{array}$ & $\begin{array}{l}\text { Compliance: } \\
100 \%\end{array}$ & Compliance: 0 \\
\hline
\end{tabular}

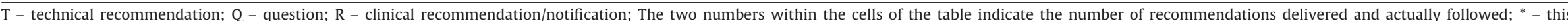
recommendation is sent to patients taking insulin or to patients replying "yes" to the question in the column to the left.

Table A12

Patient-by-patient results summary for GDM patients.

\begin{tabular}{|c|c|c|c|c|c|c|c|c|c|c|}
\hline Patient & $\begin{array}{l}\text { BG comp } \\
\text { measure } 4 \\
\text { a day }\end{array}$ & $\begin{array}{l}\text { BG comp } \\
\text { monitoring } \\
\text { plan }\end{array}$ & $\begin{array}{l}\text { Mean BG } \\
\text { values } \\
\text { fasting/post- } \\
\text { meal }\end{array}$ & $\begin{array}{l}\text { \% Normal } \\
\text { fasting/post- } \\
\text { meal } \\
\text { BG }\end{array}$ & $\begin{array}{l}\text { BP comp } \\
\text { monitoring } \\
\text { plan }\end{array}$ & $\begin{array}{l}\text { Mean BP } \\
\text { values: sys- } \\
\text { tolic/diastolic }\end{array}$ & $\begin{array}{l}\text { \% Normal } \\
\text { BP Sys- } \\
\text { tolic/Diastolic }\end{array}$ & $\begin{array}{l}\text { Ketonuria } \\
\text { comp }\end{array}$ & $\begin{array}{l}\text { Average number of } \\
\text { negative ketonuria } \\
(-,+\mid-) \text { and positive } \\
\text { ketonuria }(+,++) \text { values } \\
\text { per month }\end{array}$ & $\begin{array}{l}\% \text { Negative } \\
\text { ketonuria }\end{array}$ \\
\hline P1 & $\mathrm{H}$ & $\mathrm{H}$ & $105.20 / 130.24$ & $91.2 \% / 70.1 \%$ & $\mathrm{~L}(\mathrm{M})$ & $115.33 / 69.83(\sqrt{ })$ & $100.0 \% / 100.0 \%$ & $\mathrm{H}(\mathrm{H})$ & $20.80 / 0.00$ & $100.0 \%$ \\
\hline P2 & $\mathrm{H}$ & $\mathrm{H}$ & 94.66/123.92 & $93.3 \% / 88.2 \%$ & $\mathrm{H}(\mathrm{H})$ & $98.11 / 68.11(\sqrt{ })$ & $100.0 \% / 100.0 \%$ & $\mathrm{H}$ & $20.80 / 6.40$ & $76.5 \%$ \\
\hline P3 & M & $\mathrm{H}$ & $92.27 / 104.83$ & $91.7 \% / 98.8 \%$ & $\mathrm{~L}$ & $90.67 / 60.50(\sqrt{ })$ & $83.3 \% / 100.0 \%$ & $\mathrm{H}(\mathrm{H})$ & $28.00 / 0.00$ & $100.0 \%$ \\
\hline P4 & $\mathrm{H}$ & $\mathrm{H}$ & $89.33 / 130.22$ & $97.3 \% / 72.0 \%$ & $\mathrm{H}(\mathrm{H})$ & $103.30 / 64.87(\sqrt{ })$ & $100.0 \% / 100.0 \%$ & $\mathrm{H}(\mathrm{H})$ & $20.00 / 0.89$ & $95.7 \%$ \\
\hline P5 & $\mathrm{H}(\mathrm{H})$ & $\mathrm{H}(\mathrm{H})$ & $83.97 / 102.96$ & $99.6 \% / 98.4 \%$ & $\mathrm{H}(\mathrm{H})$ & $92.38 / 57.31(\sqrt{ })$ & $87.5 \% / 100.0 \%$ & $\mathrm{H}$ & $24.00 / 5.71$ & $80.8 \%$ \\
\hline P6 & $\mathrm{H}$ & $\mathrm{H}$ & $87.00 / 118.96$ & $99.5 \% / 86.3 \%$ & $\mathrm{H}(\mathrm{L})$ & $90.50 / 59.83(\sqrt{ })$ & $100.0 \% / 100.0 \%$ & $\mathrm{H}(\mathrm{H})$ & $17.14 / 0.00$ & $100.0 \%$ \\
\hline P7 & $\mathrm{H}$ & $\mathrm{H}$ & $112.78 / 135.10$ & $89.7 \% / 65.7 \%$ & $\mathrm{H}(\mathrm{H})$ & $86.47 / 52.86(\sqrt{ })$ & $83.3 \% / 86.1 \%$ & $\mathrm{M}(\mathrm{H})$ & $21.85 / 0.62$ & $97.3 \%$ \\
\hline P8 & $\mathrm{M}(\mathrm{H})$ & $\mathrm{H}(\mathrm{H})$ & $94.39 / 108.75$ & $96.3 \% / 92.6 \%$ & $\mathrm{H}(\mathrm{L})$ & $94.91 / 61.38(\sqrt{ })$ & $93.8 \% / 100.0 \%$ & $\mathrm{H}(\mathrm{H})$ & $27.69 / 0.00$ & $100.0 \%$ \\
\hline P9 & M & $\mathrm{H}$ & $95.59 / 118.01$ & $98.0 \% / 81.3 \%$ & $\mathrm{H}(\mathrm{L})$ & $95.67 / 61.67(\sqrt{ })$ & $100.0 \% / 100.0 \%$ & $\mathrm{H}(\mathrm{H})$ & $27.27 / 0.73$ & $97.4 \%$ \\
\hline P10 & $\mathrm{H}$ & $\mathrm{H}$ & $87.13 / 122.84$ & $98.6 \% / 81.7 \%$ & $M(L)$ & $109.80 / 73.40(\sqrt{ })$ & $100.0 \% / 100.0 \%$ & $\mathrm{H}(\mathrm{H})$ & $28.80 / 0.00$ & $100.0 \%$ \\
\hline P12 & M & $\mathrm{H}$ & $90.33 / 111.25$ & $97.2 \% / 94.4 \%$ & $\mathrm{H}(\mathrm{H})$ & $97.83 / 65.00(\sqrt{ })$ & $100.0 \% / 100.0 \%$ & $\mathrm{H}(\mathrm{H})$ & $27.43 / 0.00$ & $100.0 \%$ \\
\hline P13 & M & $\mathrm{H}$ & $90.85 / 121.34$ & $96.4 \% / 88.8 \%$ & $M(H)$ & $100.69 / 71.31(\sqrt{ })$ & $100.0 \% / 100.0 \%$ & $\mathrm{H}(\mathrm{H})$ & $28.00 / 0.50$ & $98.2 \%$ \\
\hline P14 & $\mathrm{H}$ & $\mathrm{H}$ & $82.84 / 118.75$ & $97.6 \% / 90.6 \%$ & $\mathrm{H}(\mathrm{H})$ & $98.60 / 63.03(\sqrt{ })$ & $93.3 \% / 93.3 \%$ & $\mathrm{H}(\mathrm{H})$ & $22.80 / 2.40$ & $90.5 \%$ \\
\hline P15 & $\mathrm{H}$ & $\mathrm{H}$ & $99.84 / 119.08$ & $91.4 \% / 86.4 \%$ & $\mathrm{H}$ & $105.91 / 69.22(\sqrt{ })$ & $93.8 \% / 96.9 \%$ & $\mathrm{H}$ & $16.00 / 6.67$ & $70.6 \%$ \\
\hline P16 & $\mathrm{H}$ & $\mathrm{H}$ & $102.25 / 123.91$ & $82.5 \% / 90.5 \%$ & $\mathrm{H}(\mathrm{H})$ & $106.04 / 63.74(\sqrt{ })$ & $100.0 \% / 100.0 \%$ & $\mathrm{H}(\mathrm{H})$ & $27.38 / 0.00$ & $100.0 \%$ \\
\hline P17 & $\mathrm{H}$ & $\mathrm{H}$ & $91.41 / 115.80$ & $95.0 \% / 88.2 \%$ & $\mathrm{H}(\mathrm{H})$ & $110.88 / 79.06(\sqrt{ })$ & $93.8 \% / 93.8 \%$ & $\mathrm{H}(\mathrm{H})$ & $19.43 / 0.00$ & $100.0 \%$ \\
\hline P18 & $\mathrm{H}$ & $\mathrm{H}$ & $82.38 / 113.88$ & $99.5 \% / 94.6 \%$ & $\mathrm{H}(\mathrm{H})$ & $87.22 / 58.67(\sqrt{ })$ & $77.8 \% / 100.0 \%$ & $\mathrm{H}(\mathrm{H})$ & $27.43 / 0.00$ & $100.0 \%$ \\
\hline P19 & $\mathrm{H}$ & $\mathrm{H}$ & $102.86 / 127.62$ & $89.4 \% / 82.3 \%$ & $\mathrm{H}$ & $102.56 / 56.81(\sqrt{ })$ & $98.8 \% / 93.8 \%$ & $\mathrm{H}(\mathrm{H})$ & $26.80 / 0.00$ & $100.0 \%$ \\
\hline P20 & $\mathrm{H}$ & $\mathrm{H}$ & $96.55 / 118.59$ & $87.5 \% / 91.3 \%$ & $\mathrm{H}(\mathrm{L})$ & $111.88 / 71.13(\sqrt{ })$ & $100.0 \% / 100.0 \%$ & $\mathrm{H}(\mathrm{H})$ & $25.33 / 0.00$ & $100.0 \%$ \\
\hline \multirow[t]{3}{*}{ Mode and\% } & H 74\% & H $100 \%$ & $\sqrt{ }(\leq 95 \mathrm{mg} / \mathrm{dL})$ & Avg and stdev & H $84 \%(62.5)$ & $\sqrt{ } 100 \%$ & Avg and stdev & H 95\% (100\%) & $\sqrt{ }$ (only negative) & \\
\hline & & & $63 \%$ & $94 \pm 4.48 /$ & & & $95.0 \pm 7.1 /$ & & $58 \%$ & \\
\hline & & & $\sqrt{ } \leq 140100 \%$ & $86.4 \pm 8.9$ & & & $98.1 \pm 3.8 \%$ & & & \\
\hline
\end{tabular}

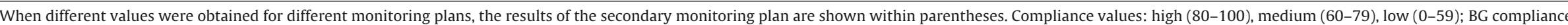

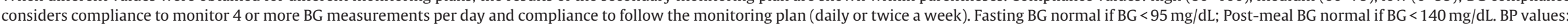
$\sqrt{ }$ normal (SBP within $[85,130]$, DBP within $[50,90]$ ). 
Table A13

AF care providers' compliance to patient-specific recommendations.

\begin{tabular}{|c|c|c|c|}
\hline Patient & \# days on MobiGuide & Cardioversion advice & ECG summary \\
\hline 1 & 96 & $0 ; 0$ & $90 ; 21$ \\
\hline 2 & 78 & $0 ; 0$ & $107 ; 39$ \\
\hline 3 & 98 & $0 ; 0$ & $189 ; 18$ \\
\hline 4 & 91 & $0 ; 0$ & $45 ; 28$ \\
\hline 5 & 90 & $0 ; 0$ & $42 ; 19$ \\
\hline 6 & 136 & $2 ; 2$ & $243 ; 25$ \\
\hline 7 & 259 & $0 ; 0$ & $368 ; 81$ \\
\hline 8 & 89 & $0 ; 0$ & $163 ; 45$ \\
\hline 9 & 249 & $0 ; 0$ & $174 ; 41$ \\
\hline 10 & 86 & $0 ; 0$ & $48 ; 17$ \\
\hline \multirow[t]{2}{*}{ Mean and Stdev (Mode and\%) } & $127.2 \pm 68.6$ days $\cong$ & Compliance was 1 for the & Average per week: $8.05 \pm 3.9$ \\
\hline & $18 \pm 10$ week & $\begin{array}{l}\text { patient for which cardioversion } \\
\text { advice was delivered }\end{array}$ & Average viewing: $0.3 \pm 0.15$ \\
\hline
\end{tabular}

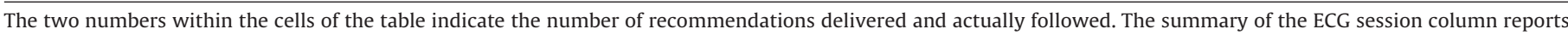
number of views generated followed by the number of viewing sessions (in which at least one view has been viewed).

Table A14

GDM care providers' compliance to patient-specific recommendations.

\begin{tabular}{|c|c|c|c|}
\hline Patient & $\begin{array}{l}\text { Consider starting insulin ( } 2 \\
\text { abnormally-high BG values in a } \\
\text { week or high BG and care } \\
\text { provider notified before) }\end{array}$ & $\begin{array}{l}\text { Change nutritional prescription } \\
\text { (high BG and care provider not } \\
\text { notified before) }\end{array}$ & $\begin{array}{l}\text { A meeting should be scheduled } \\
\text { with the patient to balance } \\
\text { patient's diet ( } 2 \text { positive } \\
\text { ketonuria values) }\end{array}$ \\
\hline $1^{\mathrm{a}}$ & $1 ; 1$ & & \\
\hline 2 & $0 ; 0$ & & \\
\hline 3 & $1 ; 0$ & $1 ; 0$ & \\
\hline $4^{\mathrm{a}}$ & $1 ; 1$ & & \\
\hline 5 & $1 ; 0$ & $1 ; 0$ & $1 ; 0$ \\
\hline 6 & $5 ; 0$ & & \\
\hline $7^{\mathrm{a}}$ & $1 ; 1$ & & $1 ; 0$ \\
\hline $8^{\mathrm{a}}$ & $1 ; 1$ & $1 ; 0$ & \\
\hline $9^{\mathrm{a}}$ & $2 ; 1$ & & \\
\hline 10 & $4 ; 0$ & & \\
\hline 12 & $2 ; 0$ & & \\
\hline $13^{a}$ & $1 ; 1$ & & \\
\hline 14 & $8 ; 0$ & & \\
\hline $15^{\mathrm{a}}$ & $1 ; 1$ & $1 ; 0$ & \\
\hline $16^{\mathrm{a}}$ & $2 ; 1$ & & \\
\hline 17 & $6 ; 0$ & & \\
\hline 18 & $2 ; 0$ & $1 ; 1$ & \\
\hline $19^{\mathrm{a}}$ & $3 ; 1$ & $1 ; 0$ & \\
\hline $20^{\mathrm{a}}$ & $1 ; 1$ & $1 ; 0$ & \\
\hline Compliance & 0.26 & 0.14 & 0 \\
\hline
\end{tabular}

The two numbers within the cells of the table indicate the number of recommendations delivered and actually followed.

a Patient started an insulin treatment following MobiGuide recommendation. For these patients, only the first recommendation to start insulin was counted.

\section{Appendix B. Detailed results of user satisfaction and \\ quality of life}

Tables B1 and B2

Table B1

Results of patients' end-of-study questionnaires: number of patients who rated each question as $1,2,3,4$, and 5 .

\begin{tabular}{|c|c|c|c|}
\hline $\begin{array}{l}\text { Question } \\
\text { topic }\end{array}$ & $\begin{array}{l}\text { Exact } \\
\text { phrasing }\end{array}$ & $\mathrm{AF}$ & GDM \\
\hline \multirow[t]{6}{*}{$\begin{array}{l}\text { System increased patients' } \\
\text { confidence }\end{array}$} & $\begin{array}{l}\text { AF: I think that the system helped me to be more confident with my decisions when taking } \\
\text { care of AF: } 1=\text { totally disagree; } 5=\text { totally agree } \\
\text { GDM: Do you think that MG has improved your perception regardless diabetes management? } \\
\text { With MG I feel myself: } 1=\text { less safe; } 5=\text { more safe }\end{array}$ & $1: 1$ & $1: 0$ \\
\hline & & $2: 1$ & $2: 1$ \\
\hline & & $3: 2$ & $3: 4$ \\
\hline & & $4: 4$ & $4: 8$ \\
\hline & & $5: 0$ & $5: 4$ \\
\hline & & $\mathrm{N} / \mathrm{A}: 1$ & \\
\hline \multirow{5}{*}{$\begin{array}{l}\text { System improved peace of } \\
\text { mind on travel }\end{array}$} & The system improved my peace of mind when travelling away from home & $1: 0$ & Not asked \\
\hline & & 2:0 & \\
\hline & & $3: 1$ & \\
\hline & & 4:6 & \\
\hline & & $5: 1$ & \\
\hline
\end{tabular}


Table B1 (Continued)

\begin{tabular}{|c|c|c|c|}
\hline $\begin{array}{l}\text { Question } \\
\text { topic }\end{array}$ & $\begin{array}{l}\text { Exact } \\
\text { phrasing }\end{array}$ & $\mathrm{AF}$ & GDM \\
\hline \multirow[t]{6}{*}{$\begin{array}{l}\text { I like the system's ability to } \\
\text { adapt to context }\end{array}$} & $\begin{array}{l}\text { I like the fact that the system can adapt to my daily life and context changes: } 1=\text { totally } \\
\text { disagree; } 5=\text { totally agree }\end{array}$ & $1: 0$ & $1: 0$ \\
\hline & & $2: 0$ & $2: 2$ \\
\hline & & $3: 1$ & $3: 3$ \\
\hline & & $4: 3$ & $4: 8$ \\
\hline & & $5: 3$ & $5: 4$ \\
\hline & & N/A:2 & \\
\hline \multirow[t]{6}{*}{$\begin{array}{l}\text { App did/did not complicate } \\
\text { patients' lives }^{\mathrm{a}}\end{array}$} & $\begin{array}{l}\text { AF: I think that using the app has complicated my daily life: } 1=\text { totally disagree; } 5=\text { totally } \\
\text { agree }\end{array}$ & $1: 2$ & $1: 0$ \\
\hline & $\begin{array}{l}\text { GDM: I think that using the app has NOT complicated my daily life: } 1=\text { totally disagree; } \\
5=\text { totally agree }\end{array}$ & & \\
\hline & & $2: 1$ & $2: 0$ \\
\hline & & $3: 4$ & $3: 2$ \\
\hline & & $4: 2$ & $4: 10$ \\
\hline & & $5: 0$ & $5: 5$ \\
\hline \multirow[t]{6}{*}{$\begin{array}{l}\text { System reduces care } \\
\text { providers' response time }\end{array}$} & $\begin{array}{l}\text { System reduces the activation time of the healthcare personnel whenever an intervention is } \\
\text { required (e.g., waiting time for a visit is shortened) }\end{array}$ & $1: 0$ & Not asked \\
\hline & & $2: 1$ & \\
\hline & & $3: 1$ & \\
\hline & & $4: 0$ & \\
\hline & & $5: 0$ & \\
\hline & & N/A:7 & \\
\hline \multirow{6}{*}{$\begin{array}{l}\text { System improved } \\
\text { interaction with } \\
\text { clinicians }\end{array}$} & The system improved the interaction with my doctor & $1: 0$ & Not asked \\
\hline & & $2: 0$ & \\
\hline & & $3: 3$ & \\
\hline & & $4: 5$ & \\
\hline & & $5: 0$ & \\
\hline & & N/A:1 & \\
\hline \multirow[t]{5}{*}{$\begin{array}{l}\text { Recommending the system } \\
\text { to other patients }\end{array}$} & $\begin{array}{l}\text { I would recommend the system to other }(\mathrm{AF} / \mathrm{GDM}) \text { patients } 1=\text { totally disagree; } 5=\text { totally } \\
\text { agree }\end{array}$ & $1: 0$ & $1: 0$ \\
\hline & & $2: 0$ & $2: 1$ \\
\hline & & $3: 0$ & $3: 0$ \\
\hline & & $4: 0$ & 4:9 \\
\hline & & $5: 9$ & $5: 7$ \\
\hline \multirow{2}{*}{$\begin{array}{l}\text { Recommending the system } \\
\text { to a friend }\end{array}$} & Would you recommend the system to a friend of yours? Y/N & Y:9 & Y:15 \\
\hline & & $\mathrm{N}: 0$ & $\mathrm{~N}: 1$ \\
\hline \multirow[t]{2}{*}{ Continue to use the system } & AF: Would you use the system in your daily routine (after this study)? Y/N & Y:8 & Y:12 \\
\hline & GDM: Would you use MobiGuide again? Y/N & $\mathrm{N}: 1$ & $\mathrm{~N}: 2$ \\
\hline \multirow[t]{2}{*}{ Paying for the system } & AF: If yes, would you be willing to pay something or using it? Y/N & Y:7 & $\mathrm{Y}: 3$ \\
\hline & GDM: Would you pay for MobiGuide? Y/N & $\mathrm{N}: 2$ & $\mathrm{~N}: 12$ \\
\hline
\end{tabular}

a Note the opposite phrasing of this question for AF vs. GDM.

Table B2

AF and GDM care providers' response to the questionnaires: number of clinicians who rated each question as $1,2,3,4$, and 5 .

\begin{tabular}{|c|c|c|c|}
\hline & \multicolumn{2}{|l|}{$\mathrm{AF}$} & \multirow{2}{*}{$\begin{array}{l}\text { GDM } \\
\text { Physicians (4) and nurses (2) }\end{array}$} \\
\hline & Physician & Nurse & \\
\hline Positive addition to patient & 2 & 5 & $\begin{array}{l}1: 0 \\
2: 0 \\
3: 0 \\
\mathbf{4}: 5 \\
5: 1\end{array}$ \\
\hline Positive addition to our organization & 3 & 4 & $\begin{array}{l}1: 0 \\
2: 0 \\
3: 1 \\
\mathbf{4}: 5 \\
5: 0\end{array}$ \\
\hline Important part of staffing & 3 & 4 & $\begin{array}{l}1: 0 \\
2: 0 \\
3: 2 \\
4: 3 \\
5: 1\end{array}$ \\
\hline
\end{tabular}


Table B2 (Continued)

\begin{tabular}{|c|c|c|c|}
\hline & \multicolumn{2}{|l|}{$\mathrm{AF}$} & \multirow{2}{*}{$\begin{array}{l}\text { GDM } \\
\text { Physicians (4) and nurses (2) }\end{array}$} \\
\hline & Physician & Nurse & \\
\hline MobiGuide makes it easier to manage patients & 5 & 4 & $\begin{array}{l}1: 0 \\
2: 0 \\
3: 2 \\
\mathbf{4} \mathbf{4} \\
5: 0\end{array}$ \\
\hline MobiGuide makes it quicker to manage patients & 3 & 4 & $\begin{array}{l}1: 0 \\
2: 2 \\
3: 2 \\
4: 2 \\
5: 0\end{array}$ \\
\hline Using MobiGuide I am likely to care better for my patients & 4 & 3 & $\begin{array}{l}1: 0 \\
2: 0 \\
3: 2 \\
\mathbf{4} \mathbf{4} \\
5: 0\end{array}$ \\
\hline MobiGuide presents a more equitable management process & 3 & 5 & $\begin{array}{l}1: 0 \\
2: 0 \\
3: 3 \\
4: 3 \\
5: 0\end{array}$ \\
\hline I am satisfied with MobiGuide's support for patient management & 3 & 5 & $\begin{array}{l}1: 0 \\
2: 0 \\
3: 1 \\
\mathbf{4 : 4} \\
5: 1\end{array}$ \\
\hline I manage patients in a timely manner using MobiGuide & 5 & 4 & $\begin{array}{l}1: 0 \\
2: 1 \\
\mathbf{3 : 4} \\
4: 1 \\
5: 0\end{array}$ \\
\hline I'm able to identify priorities using MobiGuide & 5 & 4 & $\begin{array}{l}1: 0 \\
2: 0 \\
3: 0 \\
\mathbf{4}: \mathbf{6} \\
5: 0\end{array}$ \\
\hline MobiGuide's data quality-aware features increases the safety of outpatients & 5 & 4 & $\begin{array}{l}1: 0 \\
2: 0 \\
3: 0 \\
4: 5 \\
5: 1\end{array}$ \\
\hline
\end{tabular}

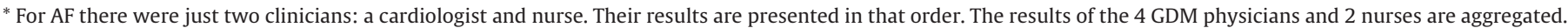

\section{Appendix C. Quality of Life results for AF patients}

Tables C1 and C2

Table C1

Results of the pre and post analysis of EuroQoL questionnaires.

\begin{tabular}{|c|c|c|c|c|c|c|c|c|c|c|c|c|c|c|}
\hline \multirow[t]{2}{*}{ Patient } & \multicolumn{2}{|c|}{ mobility } & \multicolumn{2}{|c|}{ self-care } & \multicolumn{2}{|c|}{ usual activity } & \multicolumn{2}{|c|}{ pain/discomfort } & \multicolumn{2}{|c|}{$\begin{array}{l}\text { anxiety/ } \\
\text { depression }\end{array}$} & \multicolumn{2}{|c|}{ utility coeff. } & \multicolumn{2}{|c|}{ analogue score } \\
\hline & pre & post & pre & post & pre & post & pre & post & pre & post & pre & post & pre & post \\
\hline 1 & 1 & 4 & 1 & 1 & 1 & 3 & 2 & 4 & 2 & 1 & 0.768 & 0.423 & 70 & 50 \\
\hline 2 & 1 & 4 & 1 & 1 & 1 & 1 & 2 & 1 & 1 & 2 & 0.837 & 0.757 & 20 & 80 \\
\hline 3 & 1 & 1 & 1 & 1 & 1 & 1 & 1 & 1 & 2 & 1 & 0.879 & 1 & 90 & 90 \\
\hline
\end{tabular}


Table C1 (Continued)

\begin{tabular}{|c|c|c|c|c|c|c|c|c|c|c|c|c|c|c|}
\hline \multirow[t]{2}{*}{ Patient } & \multicolumn{2}{|c|}{ mobility } & \multicolumn{2}{|c|}{ self-care } & \multicolumn{2}{|c|}{ usual activity } & \multicolumn{2}{|c|}{ pain/discomfort } & \multicolumn{2}{|c|}{$\begin{array}{l}\text { anxiety/ } \\
\text { depression }\end{array}$} & \multicolumn{2}{|c|}{ utility coeff. } & \multicolumn{2}{|c|}{ analogue score } \\
\hline & pre & post & pre & post & pre & post & pre & post & pre & post & pre & post & pre & post \\
\hline 4 & 2 & & 2 & & 2 & & 1 & & 2 & & & & 60 & \\
\hline 5 & 2 & 1 & 1 & 2 & 2 & 1 & 1 & 1 & 2 & 2 & 0.627 & 0.803 & 70 & 75 \\
\hline 6 & 1 & 1 & 1 & 1 & 1 & 1 & 1 & 1 & 1 & 1 & 1 & 1 & 75 & 90 \\
\hline 7 & 1 & 1.2 & 1 & 1.1 & 1 & 1.1 & 1 & 1.1 & 1 & 1.4 & 1 & 0.9 & 90 & 81.1 \\
\hline 8 & 1 & 1 & 1 & 1 & 1 & 1 & 2 & 1 & 1 & 1 & 0.837 & 1 & 70 & 95 \\
\hline 9 & 1 & 2 & 2 & 2 & 2 & 2 & 2 & 2 & 5 & 3 & 0.2 & 0.391 & 60 & 80 \\
\hline 10 & 1 & & 1 & & 2 & & 1 & & 2 & & 0.837 & & 70 & \\
\hline
\end{tabular}

End of study quality of life questionnaire was not completed by patients 4 and 10 .

Note that the pre-MobiGuide analogue score given by one of the patients (patient 2 ) seems too low and does not correspond to his/her overall score (0.83).

Table C2

Results of the pre \& post analysis of AFEQT questionnaire (high scores indicate better quality of life).

\begin{tabular}{|c|c|c|c|c|c|c|c|c|c|c|}
\hline \multirow[t]{2}{*}{ Patient } & \multicolumn{2}{|c|}{ score_symptoms } & \multicolumn{2}{|c|}{ score_activities } & \multicolumn{2}{|c|}{ score_treatement } & \multicolumn{2}{|c|}{ score_overall } & \multicolumn{2}{|c|}{ treatment_satisfaction } \\
\hline & pre & post & pre & post & pre & post & pre & post & pre & post \\
\hline 1 & 67 & 88 & 50 & 42 & 61 & 42 & 57 & 52 & 42 & 33 \\
\hline 2 & 100 & & 100 & & 97 & & 99 & & 100 & \\
\hline 3 & 46 & & 100 & & 83 & & 82 & & & \\
\hline 4 & 100 & 62 & 52 & 29 & 89 & 78 & 75 & 53 & 100 & 67 \\
\hline 5 & 100 & 88 & 27 & 85 & 42 & 78 & 49 & 83 & 67 & 83 \\
\hline 6 & 92 & 100 & 29 & 46 & 75 & 75 & 58 & 68 & 67 & 67 \\
\hline 7 & 62 & 63 & 92 & 81 & 39 & 36 & 68 & 62 & 83 & 100 \\
\hline 8 & 96 & 79 & 81 & 77 & 100 & 94 & 91 & 83 & 50 & 50 \\
\hline 9 & 54 & 58 & 79 & 70 & 75 & 83 & 72 & 72 & 75 & 75 \\
\hline 10 & 100 & 100 & 83 & 65 & 54 & 53 & 79 & 69 & 67 & 100 \\
\hline
\end{tabular}

\section{References}

[1] D. DeBronkart, E.J. Topol, Let Patients Help! CreateSpace, Independent Publishing Platform, 2013.

[2] R.M. Anderson, M.M. Funnell, Patient empowerment: myths and misconceptions, Patient Educ. Couns. 79 (3) (2010) 277-282.

[3] C. Jacova, J. McGrenere, H.S. Lee, W.W. Wang, Huray S. Le, E.F. Corenblith, et al., C-TOC (Cognitive testing on computer): investigating the usability and validity of a novel self-administered cognitive assessment tool in aging and early dementia, Alzheimer Dis. Assoc. Disord. 29 (3) (2014) 213-221.

[4] X. Zhou, Y. Chen, C. Tang, L. Wilcox, K. Zheng, Opportunities and challenges in designing interactive systems for patient-Provider communication, Workshop on Interactive Systems in Healthcare (2012).

[5] I. Aujoulat, W. d'Hoore, A. Deccache, Patient empowerment in theory and practice: polysemy or cacophony? Patient Educ. Couns. 66 (1) (2007) 13-20.

[6] S. Scambler, P. Newton, K. Asimakopoulou, The context of empowerment and self-care within the field of diabetes, Healrh 18 (6) (2014) 545-560.

[7] W. Kuijpers, W.G. Groen, N.K. Aaronson, W.H. van Harten, A systematic review of web-based interventions for patient empowerment and physical activity in chronic diseases: relevance for cancer survivors, J. Med. Internet Res. 15 (2) (2013) e37.

[8] E.M. Borycki, M.S. Househ, A.W. Kushniruk, C. Nohr, H. Takeda, Empowering patients: making health information and systems safer for patients and the public. contribution of the IMIA health informatics for patient safety working group, Yearb. Med. Inf. 7 (1) (2012) 56-64.

[9] M.J. Field, K.N. Lohr, Guidelines for Clinical Practice: Directions for a New Program, Institute of Medicine National Academy Press, Washington, DC, 1990.

[10] M. Peleg, Computer-interpretable clinical guidelines: a methodological review, J. Biomed. Inf. 46 (4) (2013) 744-763.

[11] A. Latoszek-Berendsen, H. Tange, Herik H.J van den, A. Hasman, From clinical practice guidelines to computer-interpretable guidelines. A literature overview, Methods Inf. Med. 49 (6) (2010) 550-570.

[12] M. Peleg, T. Broens, A. González-ferrer, E. Shalom, Architecture for a ubiquitous context-aware clinical guidance system for patients and care providers, Joint 6th International Workshop on Process-oriented Information Systems in Healthcare/5th International Workshop on Knowledge Representation for Health Care (ProHealth'13/KR4HC'13) (2013).

[13] M. Peleg, Y. Shahar, S. Quaglini, A. Fux, G. García-Sáez, MobiGuide: a personalized and patient-centric decision-support system and its evaluation in the atrial fibrillation and gestational diabetes domains, User Model. User Adapt. Interact. (2017), http://dx.doi.org/10.1007/s11257-017-9190-5 (in print).

[14] M. Peleg, Y. Shahar, S. Quaglini, Making healthcare more accessible, better, faster, and cheaper: the MobiGuide Project, Eur. J. ePract. 20 (2013) 5-20.

[15] M. Peleg, S. Keren, Y. Denekamp, Mapping computerized clinical guidelines to electronic medical records: knowledge-data ontological mapper (KDOM), J. Biomed. Inf. 41 (1) (2008) 180-201.
[16] E. Shalom, Y. Shahar, Y. Parmet, E. Lunenfeld, A multiple-scenario assessment of the effect of a continuous-care, guideline-based decision support system on clinicians' compliance to clinical guidelines, Int. J. Med. Inf. 84 (4) (2015) 248-262 (in press)

[17] E. Shalom, Y. Shahar, E. Lunenfeld, An architecture for a continuous, user-driven, and data-driven application of clinical guidelines and its evaluation, J. Biomed. Inf. 59 (2016) 130-148.

[18] D. Boaz, Y. Shahar, A framework for distributed mediation of temporal-abstraction queries to clinical databases, Artif. Intell. Med. 34 (1) (2005) 3-24

[19] Carlos Marcos, A. González-Ferrer, M. Peleg, C. Cavero, Solving the interoperability challenge of a distributed complex patient guidance system: a data integrator based on HL7ás Virtual Medical Record standard, J. Am. Med. Inf. Assoc. Press 22 (3) (2015) 587-599.

[20] E. Shalom, Y. Shahar, A. Goldstein, E. Ariel, S. Quaglini, L. Sacchi, et al., Enhancing Guideline-based decision support with distributed computation through local mobile application, Proceedings of the 7th Int'l Workshop on Process-oriented Information Systems in Healthcare (ProHealth 2014) Lecture Notes in Business Information Processing 202 (2014) 53-58.

[21] E. Shalom, Y. Shahar, A. Goldstein, E. Ariel, M. Sheinberger, N. Fung, et al., Implementation of the distributed guideline-based decision support model in the MobiGuide framework KR4HC/ProHealth, vol. 9485, Springer LNAI, 2015, pp. 111-125.

[22] Y. Shahar, Dynamic temporal interpretation contexts for temporal abstraction, Ann. Math. Artif. Intell. 22 (1-2) (1998) 159-192.

[23] Y. Shahar, A framework for knowledge-based temporal abstraction, Artif. Intell. 90 (1-2) (1997) 79-133.

[24] G. García-Sáez, M. Rigla, E. Shalom, M. Peleg, E. Caballero, E.J. Gómez, et al., Parallel workflows to personalize clinical guidelines recommendations: application to Gestational Diabetes Mellitus, 13th Mediterranean Conf on Medical and Biological Engineering and Computing (2013) 1409-1412.

[25] L. Sacchi, A. Fux, C. Napolitano, S. Panzarasa, M. Peleg, S. Quaglini, et al., Patient-tailored workflow patterns from clinical practice guidelines recommendations, Stud. Health Technol. Inf. 2013192 (2013) 392-396.

[26] S. Rubrichi, C. Rognoni, L. Sacchi, E. Parimbelli, C. Napolitano, A. Mazzanti, S. Quaglini, Graphical representation of life paths to better convey results of decision models to patients, Med. Decis. Making 35 (3) (2015) 398-402.

[27] L. Sacchi, S. Rubrichi, C. Rognoni, S. Panzarasa, E. Parimbelli, S. Mazzanti, et al., From decision to shared-decision: introducing patients' preferences into clinical decision analysis, Artif. Intell. Med. 65 (1) (2015) 19-28.

[28] E. Parimbelli, L. Sacchi, S. Rubrichi, A. Mazzanti, S. Quaglini, UceWeb: a web-based collaborative tool for collecting and sharing quality of life data, Methods Inf. Med. 54 (2) (2015) 156-163.

[29] Health Level Seven. HL7 Version 3 Standard: Clinical Decision Support; Virtual Medical Record (vMR) Logical Model, Release 2. 2014. (Accessed 15 February 2017) Available from: http://www.hl7.org/implement/standards/ product_brief.cfm? product_id=338. 
[30] A. González-Ferrer, M. Peleg, E. Parimbelli, E. Shalom, C. Marcos, G. Klebanov, et al., Use of the virtual medical record data model for communication among components of a distributed decision-support system, IEEE-EMBS

International Conferences on Biomedical and Health Informatics (2014) 526-530.

[31] Association EHR, Surgery EA for cardio-thoracic surgery. guidelines for the management of atrial fibrillation: the task force for the management of atria fibrillation of the european society of cardiology (ESC), Eur. Heart J. 31 (19) (2010) 2369-2429.

[32] A.J. Camm, G.Y. Lip, R. Caterina De, I. Savelieva, D. Atar, 2012 focused update of the ESC Guidelines for the management of atrial fibrillation: an update of the 2010 ESC Guidelines for the management of atrial fibrillation-developed with the special contribution of the European Heart Rhythm Association, Europace 14 (10) (2012) 1385-1413.

[33] National Collaborating Centre for Women's and Children's Health, Diabetes in Pregnancy. Management of Diabetes and Its Complications from Preconception to the Postnatal Period, 2008 (Accessed 15 February 2017)

Available from: https://www.nice.org.uk/guidance/ng3/resources/diabetesin-pregnancy-management-of-diabetes-and-its-complications-frompreconception-to-the-postnatal-period-51038446021.

[34] Royal College of Obstetricians and Gynecologists, The Royal College of Midwives. Hypertension in Pregnancy: The Management of Hypertensive Disorders During Pregnancy, 2010, pp. 1-296, August.

[35] M. Villaplana, B. Pons, M. Morillo, A. Aguilar, A. Mendez, R. Tirado, et al., Early introduction of insulin in gestational diabetes seems to prevent from birth weight abnormalities, Diabetes, Hypertension, Metabolic Syndrome \& Pregnancy Symposium (2015).
[36] MobiGuide Consorium, Monitored Patterns, Notifications and Recommendations Used in the AF and GDM CIGs of MobiGuide, 2016 (Accessed 15 February 2017) Available from: http://mis.hevra.haifa.ac.il/ $\sim$ morpeleg/MobiGuide_Patterns.pdf.

[37] J. Spertus, P. Dorian, R. Bubien, S. Lewis, D. Godejohn, M.R. Reynolds, et al., Development and validation of the Atrial Fibrillation Effect on QualiTy-of-Life (AFEQT) Questionnaire in patients with atrial fibrillation, Circ. Arrhythm. Electrophysiol. 4 (1) (2011) 15-25.

[38] C. Amezcua-Prieto, R. Olmedo-Requena, E. Jímenez-Mejías, F. Hurtado-Sánchez, J. Mozas-Moreno, P. Lardelli-Claret, et al., Changes in leisure time physical activity during pregnancy compared to the prior year: matern Child Health, J. Int. Feder. Gynecol. Obstetr. 17 (4) (2013) 632-638.

[39] I. Lamprinos, H. Demski, S. Mantwill, Y. Kabak, C. Hildebrand, M. Ploessnig, Modular ICT-based patient empowerment framework for self-management of diabetes: design perspectives and validation results, Int. J. Med. Inform. 91 (2016) 31-43, Elsevier Ireland Ltd.

[40] V.W. Wong, C. Astorga, B. Jalaludin, Gestational diabetes mellitus: a study of women who fail to attend appointments, Diabetes Spectrum. 26 (2013) 267-271.

[41] Consumer Health Information Corporation, Motivating Patients to Use Smartphone Health Apps, 2012 (Accessed 15 February 2017) Available from: http://www.consumer-health.com/motivating-patients-to-use-smartphonehealth-apps.

[42] P. Dorian, C. Burk, C.M. Mullin, R. Bubien, D. Godejohn, M.R. Reynolds, et al., Interpreting changes in quality of life in atrial fibrillation: how much change is meaningful? Am. Heart J. 166 (2) (2013) 381-387.

[43] A. Shabo, M. Peleg, E. Parimbelli, S. Quaglini, C. Napolitano, Interplay between clinical guidelines and organizational workflow systems: experience from the MobiGuide project, Methods Inf. Med. 55 (4) (2016). 